Louisiana State University

LSU Digital Commons

1998

\title{
A Case for Procedural Justice Climate: Development and Test of a Multilevel Model.
}

Stefanie Elizabeth Naumann

Louisiana State University and Agricultural \& Mechanical College

Follow this and additional works at: https://digitalcommons.Isu.edu/gradschool_disstheses

\section{Recommended Citation}

Naumann, Stefanie Elizabeth, "A Case for Procedural Justice Climate: Development and Test of a Multilevel Model." (1998). LSU Historical Dissertations and Theses. 6693.

https://digitalcommons.Isu.edu/gradschool_disstheses/6693

This Dissertation is brought to you for free and open access by the Graduate School at LSU Digital Commons. It has been accepted for inclusion in LSU Historical Dissertations and Theses by an authorized administrator of LSU Digital Commons. For more information, please contact gradetd@lsu.edu. 


\section{INFORMATION TO USERS}

This manuscript has been reproduced from the microfilm master. UMI films the text directly from the original or copy submitted. Thus, some thesis and dissertation copies are in typewriter face, while others may be from any type of computer printer.

The quality of this reproduction is dependent upon the quality of the copy submitted. Broken or indistinct print, colored or poor quality illustrations and photographs, print bleedthrough, substandard margins, and improper alignment can adversely affect reproduction.

In the unlikely event that the author did not send UMI a complete manuscript and there are missing pages, these will be noted. Also, if unauthorized copyright material had to be removed, a note will indicate the deletion.

Oversize materials (e.g., maps, drawings, charts) are reproduced by sectioning the original, beginning at the upper left-hand corner and continuing from left to right in equal sections with small overlaps. Each original is also photographed in one exposure and is included in reduced form at the back of the book.

Photographs included in the original manuscript have been reproduced xerographically in this copy. Higher quality 6" $\times 9$ " black and white photographic prints are available for any photographs or illustrations appearing in this copy for an additional charge. Contact UMI directly to order.

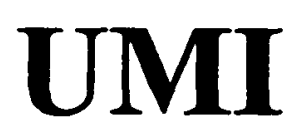

A Bell \& Howell Information Company 
Reproduced with permission of the copyright owner. Further reproduction prohibited without permission. 
A CASE FOR PROCEDURAL JUSTICE CLIMATE:

DEVELOPMENT AND TEST OF A MULTLEVEL MODEL

\author{
A Dissertation \\ Submitted to the Graduate Faculty of the \\ Louisiana State University and \\ Agricultural and Mechanical College \\ in partial fulfillment of the \\ requirements for the degree of \\ Doctor of Philosophy \\ in
}

The Interdepartmental Program of Business Administration

by

Stefanie Elizabeth Naumann

B.S., Tulane University, 1993

May 1998 
UMI Number: 9836894

UMI Microform 9836894

Copyright 1998, by UMI Company. All rights reserved.

This microform edition is protected against unauthorized copying under Title 17, United States Code.

\section{UMI \\ 300 North Zeeb Road \\ Ann Arbor, MI 48103}




\section{Acknowledgments}

I thank Dr. Nathan Bennett for his role as chair of my dissertation committee and for his invaluable mentoring throughout my graduate program. I also thank Drs. Kevin Mossholder, Cheryl Adkins, and Eric Braverman for their contributions to both my dissertation and my professional development. I thank my husband, David, and our family, who supported me during my studies at LSU. 


\section{Table of Contents}

Acknowledgments $\ldots \ldots \ldots \ldots \ldots \ldots \ldots \ldots \ldots \ldots \ldots \ldots \ldots \ldots \ldots \ldots$

List of Tables $\ldots \ldots \ldots \ldots \ldots \ldots \ldots \ldots \ldots \ldots \ldots \ldots \ldots$ iv

List of Figures $\ldots \ldots \ldots \ldots \ldots \ldots \ldots \ldots \ldots \ldots \ldots \ldots \ldots$

Abstract $\ldots \ldots \ldots \ldots \ldots \ldots \ldots \ldots \ldots \ldots \ldots \ldots \ldots \ldots$ vii

Chapter

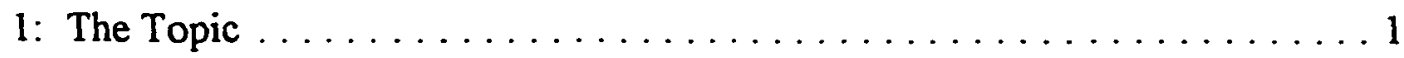

2: Model Development and Hypotheses $\ldots \ldots \ldots \ldots \ldots \ldots$

3: Method ........................... 34

4: Analyses and Results $\ldots \ldots \ldots \ldots \ldots \ldots \ldots \ldots \ldots \ldots \ldots$

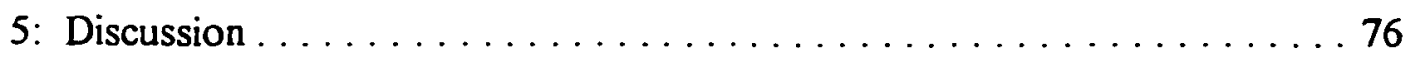

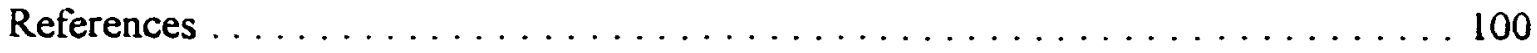

Appendix

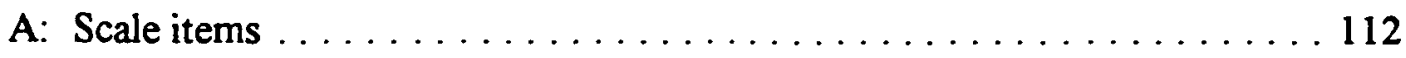

B: Employee Survey $\ldots \ldots \ldots \ldots \ldots \ldots \ldots \ldots \ldots \ldots \ldots$

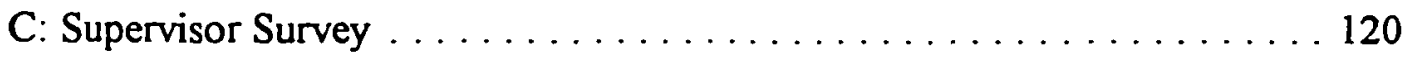

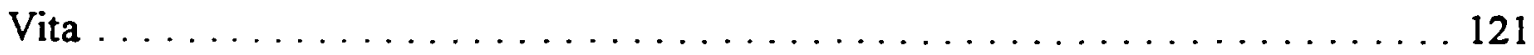

iii 


\section{List of Tables}

Table 1

Summary of Hypotheses $\ldots \ldots \ldots \ldots \ldots \ldots \ldots \ldots \ldots \ldots$

Table 2

Confirmatory Factor Analysis

on Individual Level Variables

Table 3

Descriptive Statistics for

Individual Level Variables

Table 4

Regression Analyses on

Individual Level Variables 50

Table 5

Group Level Descriptive Statistics 52

Table 6

$R^{2}$ and $s R^{2}$ for Group Level Predictors

of Procedural Justice Climate Agreement . . . . . . . . . . . . 53

Table 7

Regression Analyses on Group Level Predictors

of Procedural Justice Climate Agreement . . . . . . . . . . . . 56

Table 8

Regression Analysis: Procedural Justice Climate

Predicted by Work Group Absence . . . . . . . . . . . . . . . . . . . . 57

Table 9

HLM Analysis:

Null Model, Turnover Intentions

Table 10

HLM Analysis: Null Model, Organizational Commitment . . . . . . . . . . 63

Table 11

HLM Analysis: Null Model, OCB . . . . . . . . . . . . . 64

iv 
Table 12

HLM Analysis: Random Coefficient Regression Model,

Turnover Intentions . . . . . . . . . . . . . . . . . . . . . . . . . 66

Table 13

HLM Analysis: Random Coefficient Regression Model,

Organizational Commitment . . . . . . . . . . . . . . . . . . . 67

Table 14

HLM Analysis: Random Coefficient Regression Model,

OCB $\ldots \ldots \ldots \ldots \ldots \ldots \ldots \ldots \ldots \ldots \ldots \ldots . \ldots \ldots$

Table 15

HLM Analysis: Intercepts as Outcomes Model,

Turnover Intentions $\ldots \ldots \ldots \ldots \ldots \ldots \ldots \ldots \ldots$

Table 16

HLM Analysis: Intercepts as Outcomes Model,

Organizational Commitment . . . . . . . . . . . . . . . . 71

Table 17

HLM Analysis: Intercepts as Outcomes Model,

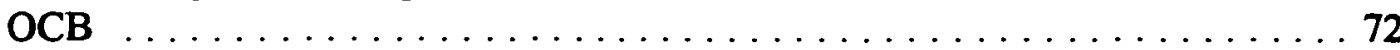

Table 18

Summary of Hypotheses and their Outcomes $\ldots \ldots \ldots \ldots \ldots 74$ 


\section{List of Figures}

Figure 1

Individual Level Relationships $\ldots \ldots \ldots \ldots \ldots \ldots \ldots \ldots \ldots$

Figure 2

Group Level Relationships $\ldots \ldots \ldots \ldots \ldots \ldots \ldots \ldots \ldots$

Figure 3

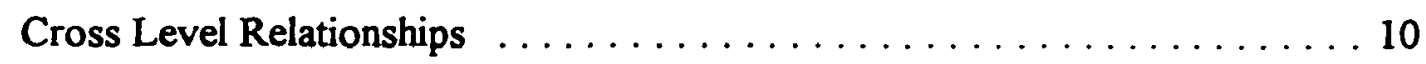

vi 


\begin{abstract}
Current conceptualizations of procedural justice focus largely on individual perceptions; no framework exists for examining procedural justice's social context. This dissertation presents a model that identifies contextual factors contributing to procedural justice climate and, in turn, a variety of work-related attitudes and behaviors associated with procedural justice climate. In general, empirical tests on data collected from 220 employees of two banks offered support for the model. Employee perceptions of leader member exchange, organizational support, and supervisor monitoring were positively associated with individual procedural justice perceptions. Work group perceptions of cohesion and supervisor visibility in demonstrating procedural justice were associated with the development of procedural justice climate. Work group demographic similarity and shared support perceptions were not associated with the development of procedural justice climate. A contextual effect was found for organizational citizenship behaviors. Specifically, procedural justice climate explained variance in organizational citizenship behaviors beyond the effects of individual procedural justice perceptions. Contextual effects were not found for organizational commitment and turnover intentions. Implications of the model for theory, research, and practice are presented.
\end{abstract}

vii 


\section{Chapter 1: The Topic \\ Introduction}

In recent years, the topic of organizational justice has received considerable attention (see Cropanzano \& Greenberg, 1997 for a review). Researchers have generally distinguished between two types of organizational justice: distributive and procedural (Greenberg, 1986; Folger \& Konovsky, 1989). Distributive justice concerns the perceived faimess of the actual value of outcomes such as pay raises (Folger \& Konovsky, 1989). In contrast, procedural justice pertains to the perceived fairness of the procedures used to arrive at outcomes (Folger \& Konovsky, 1989).

Organizational justice research can be traced back to Adams' (1965) writings about individuals' perceptions of the distributive fairness of outcome allocation. Adams' equity theory suggests that individuals are motivated to reduce the tension that results when one's ratio of outcomes (e.g., pay) to inputs (e.g., effort) is unequal to that of a comparison other (i.e., inequity). When inequity exists, individuals exhibit lower levels of job satisfaction and performance (Greenberg, 1990a; 1993). Building on the ideas of Adams (1965), Leventhal (1976) and Thibaut and Walker (1975) suggested that individuals consider procedures, not just outcomes, when making fairness evaluations. Working in the legal arena, Leventhal (1976) examined reactions to dispute resolution procedures. From this work, he identified a set of 'procedural rules' stipulating that in order for procedures to be fair, they must be applied consistently across individuals, free from bias, ethical, accurate, and representative of all individuals. Greenberg and Folger (1983) extended these procedural rules to an organizational context. Early research on 
procedural justice in organizations focused on distinguishing the construct from distributive justice (e.g., Greenberg, 1986; Sheppard \& Lewicki, 1987).

A large body of empirical research has since examined the comparative effects of procedural and distributive justice perceptions on important outcome variables (e.g., Folger \& Konovsky, 1989; Fryxell \& Gordon, 1989; Konovsky, Folger, \& Cropanzano, 1987; McFarlin \& Sweeney, 1992). For instance, procedural justice perceptions have been found to explain variance in management evaluations (Alexander \& Ruderman, 1987), supervisor evaluations (McFarlin \& Sweeney, 1992), supervisor trust (Folger \& Konovsky, 1989), and organizational commitment (Konovsky et al., 1987). In contrast, distributive justice perceptions have been found to predict current pay satisfaction (Konovsky et al., 1987), pay raise satisfaction (Folger \& Konovsky, 1989), and job satisfaction (McFarlin \& Sweeney, 1992).

\section{Statement of the Problem}

The accumulation of empirical research on organizational justice makes it timely to evaluate the current state of the theory. Reviews of the organizational justice literature (Cropanzano \& Greenberg, 1997; Greenberg, 1990b) have noted that the large volume of empirical research on distributive justice has resulted in several reconceptualizations of the construct. For instance, the mechanism through which social comparisons take place has been further specified (Berger, Zelditch, Anderson, \& Cohen, 1972). Also, individuals' choices of their 'referent others' are now thought to change over time (Stepina \& Perrewe, 1991). In addition, the equity calculation on which distributive justice is based has been modified to take into account negative values 
(Harris, 1976) as well as a more proactive consideration of reward allocation (Brockner \& Wisenfeld, 1996). In stark contrast, some have noted that the large volume of empirical research on procedural justice has not similarly resulted in conceptual refinement (Cropanzano \& Greenberg, 1997; Greenberg, 1990b). Reichers and Schneider's (1990) "life cycle of constructs" may be used to examine the current state of procedural justice theory. According to Reichers and Schneider (1990), constructs evolve through three stages of development: introduction and elaboration, evaluation and augmentation, and consolidation and accommodation. The introduction and elaboration stage is characterized by an introduction of an idea. Efforts are made toward defining the construct and providing legitimation as to its relevance. The procedural justice construct entered this stage through the early definitional works of Leventhal (1976) and Thibaut \& Walker (1975). Legitimation of procedural justice was provided by Greenberg and Folger (1983), who were the first to extend Leventhal's six procedural rules to the organizational context and validate their importance in that context (Greenberg, 1990b).

The second stage of the life cycle of constructs, evaluation and augmentation, is marked by critical reviews of constructs. Efforts are made to address problems of conceptualization, methodologies, and equivocal research findings. Attempts are made to identify moderators in order to modify current conceptualizations of the construct. It has been suggested that the procedural justice construct remains in the early segment of this stage (Cropanzano \& Greenberg, 1997; Greenberg, 1990b). Whereas some researchers have reviewed the procedural justice literature (e.g., Lind \& Tyler, 1988), no 
well-articulated re-conceptualizations of procedural justice have appeared. I argue that, though more empirical research has been conducted, the construct remains in the early stages of its conceptual development.

To this point, procedural justice has been conceptualized as mainly an individuallevel phenomenon. This individual-level focus, based on the "self-interest" or "instrumental" model (Lind \& Tyler, 1988), assumes that economic incentives facilitate perceptions of procedural justice. According to this model, individuals assess and respond with a long-term focus to organizational practices that affect them. That is, they may accept and overlook short-term economic losses if they believe that economic gains will come in the future. Thus, organizational practices that are highest in procedural justice are those that promise to yield the greatest benefits to the individual in the long run (Greenberg, 1990b).

Although the self-interest model has received empirical support (e.g., Conlon, 1993), it seems likely that other explanations may account for individuals' perceptions of procedural justice. For example, it is plausible that individuals look to others in their work group for cues when making procedural justice evaluations. I argue that the selfinterest model does not adequately address contextual factors that might affect justice perceptions and that a "procedural justice climate" operates to capture many of these contextual factors. It has been argued that in order to understand organizational behavior, it is important to examine the context in which the behavior occurs (Pfeffer \& Salancik, 1978). When context is ignored, the 'distinctive competence' of organizational behavior (i.e., the linking of several levels of analysis) is lost (Cappelli \& Sherer, 1991; 
House, Rousseau, \& Thomas-Hunt, 1995). In summary, I propose that the procedural justice construct remains in the early segment of Schneider and Reichers' (1990) second stage, evaluation and augmentation. In this dissertation, I present and test a model that advances the conceptual development of the procedural justice construct by identifying procedural justice climate. Specifically, this model identifies those workplace cues that influence individual perceptions of procedural justice and those that influence group perceptions of procedural justice. These individual and group procedural justice perceptions (i.e., procedural justice climate) are expected to have independent effects on work-related attitudes and behaviors.

\section{Theoretical Background}

As noted earlier, the existing procedural justice literature has focused on the individual level of analysis. Some researchers, however, have recognized the need to consider the social context in which justice perceptions operate. James and Cropanzano (1990) suggested that individuals observe others in their group and make judgments about how procedures experienced by the other group members affect them. In addition, Tyler and Lind (1992) have argued that a procedural justice violation against one member of a work group may be interpreted as a violation against the entire work group. Consistent with this notion, the "group values" or "relational" model (Lind \& Tyler, 1988), holds that people value their membership in groups, since groups offer symbols of identity, economic resources, and a way of validating behavior. Groups specify norms concerning fair treatment such as treating members with respect or giving them a voice in decision making (James \& Cropanzano, 1990; Tyler \& Lind, 1992). It is this 
perspective that begins to link procedural justice to its social context. Although little research has explicitly examined this notion, a recent study by Mossholder, Bennett, and Martin (in press) found that a social context measure of procedural justice explained variance in individuals' work-related attitudes beyond that explained by an individuallevel procedural justice measure. The authors explained their findings in terms of social information processing in that group members attend to what is considered fair by considering their work group's perspective. Thus, their study suggests that, consistent with the group values model, procedural justice's effect on work attitudes encompasses more than just individual perceptions; yet, no real framework for linking social context with procedural justice perceptions exists. This dissertation proposes that the work group climate literature can be used to develop such a framework.

The work group climate literature provides insight as to how contextual factors affect perceptions of procedural justice. Organizational climate has been defined as a set of shared perceptions of policies, practices, and procedures that get rewarded, supported, and expected through group interaction (Schneider, 1990; Schneider \& Reichers, 1983). Work group climates are climates that are operationalized at the group level of analysis (i.e., many different work group climates may exist in a single organization). Many criterion-referenced climates have been investigated: climates for service (Schneider, Parkington, \& Buxton, 1980), safety (Zohar, 1980), innovation (Abbey \& Dickson, 1983), new employees (Schneider \& Bartlett, 1968; 1970), labormanagement relations (Angle \& Perry, 1986), needs for power, achievement and affiliation (Litwin \& Stringer, 1968), human relations-oriented leadership (Fleishman, 
1953), creativity (Taylor, 1972), conflict resolution (Renwick, 1975), participation and control (McGregor, 1960), and retaliation against whistle-blowing (Miceli \& Near, 1985). Given the diverse array of climates described in the organizational behavior literature, it seems plausible that procedural justice climate exists as well.

Dimensions of climates are, by definition, characterized by shared perceptions of organizational policies, practices, and procedures (James, Joyce, \& Slocum, 1988). It is precisely through these policies, practices, and procedures that organizations communicate procedural justice to employees and employees form judgments (Cropanzano \& Greenberg, 1997). I suggest that several individual and work group factors act as lenses that employees use to form judgments about the faimess of these organizational practices. These justice judgments, in turn, have been shown to affect the way employees think about and behave at work (e.g., organizational citizenship behaviors; Moorman, 1991; Niehoff \& Moorman, 1993).

The purpose of this dissertation is to present and test a model that identifies contextual factors that contribute to the development of procedural justice climate; this climate is expected to affect work-related attitudes and behaviors beyond the effects of individual-level measures of procedural justice. The model in Figure 1 proposes that the quality of leader-member exchange and perceptions of organizational support and leader monitoring affect individual procedural justice perceptions. As shown in Figure 2, work group demography, work group cohesion, the visibility of supervisors in demonstrating procedural justice, and shared support perceptions are proposed to influence procedural justice climate agreement. As shown in Figure 3, individual procedural justice 


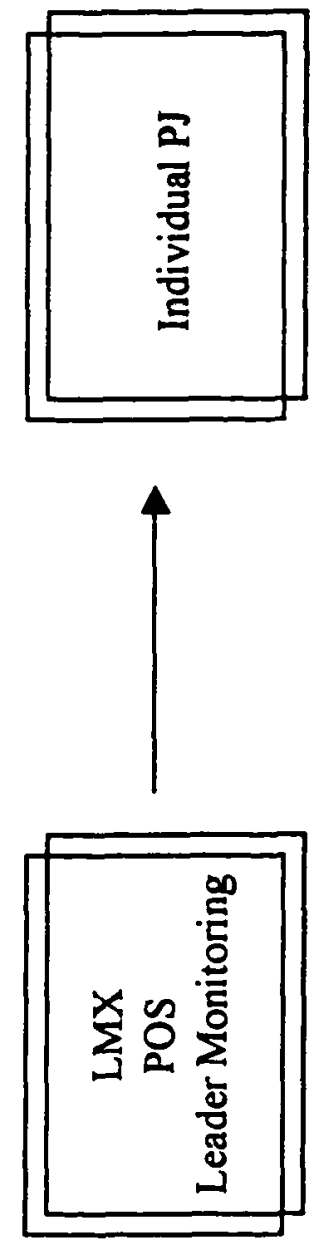

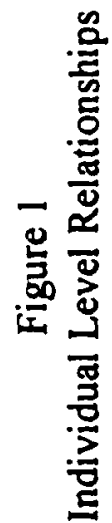

Reproduced with permission of the copyright owner. Further reproduction prohibited without permission. 


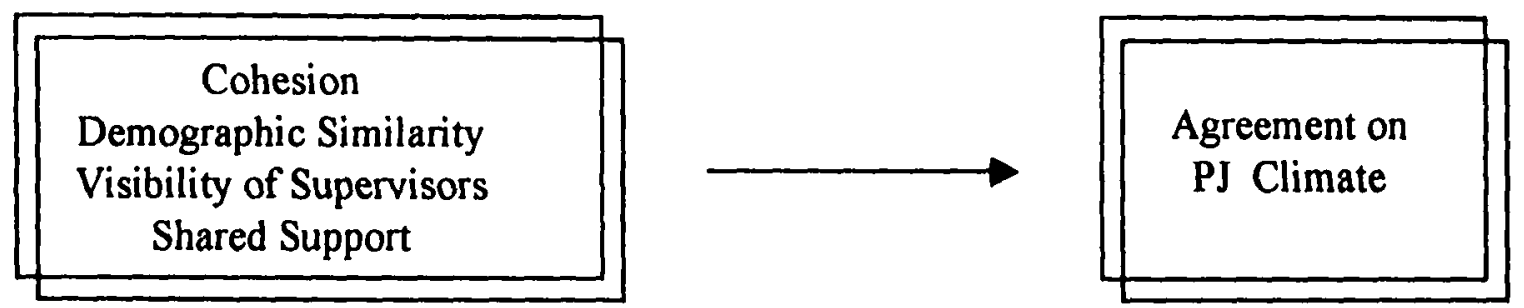

Figure 2

Group Level Relationships 

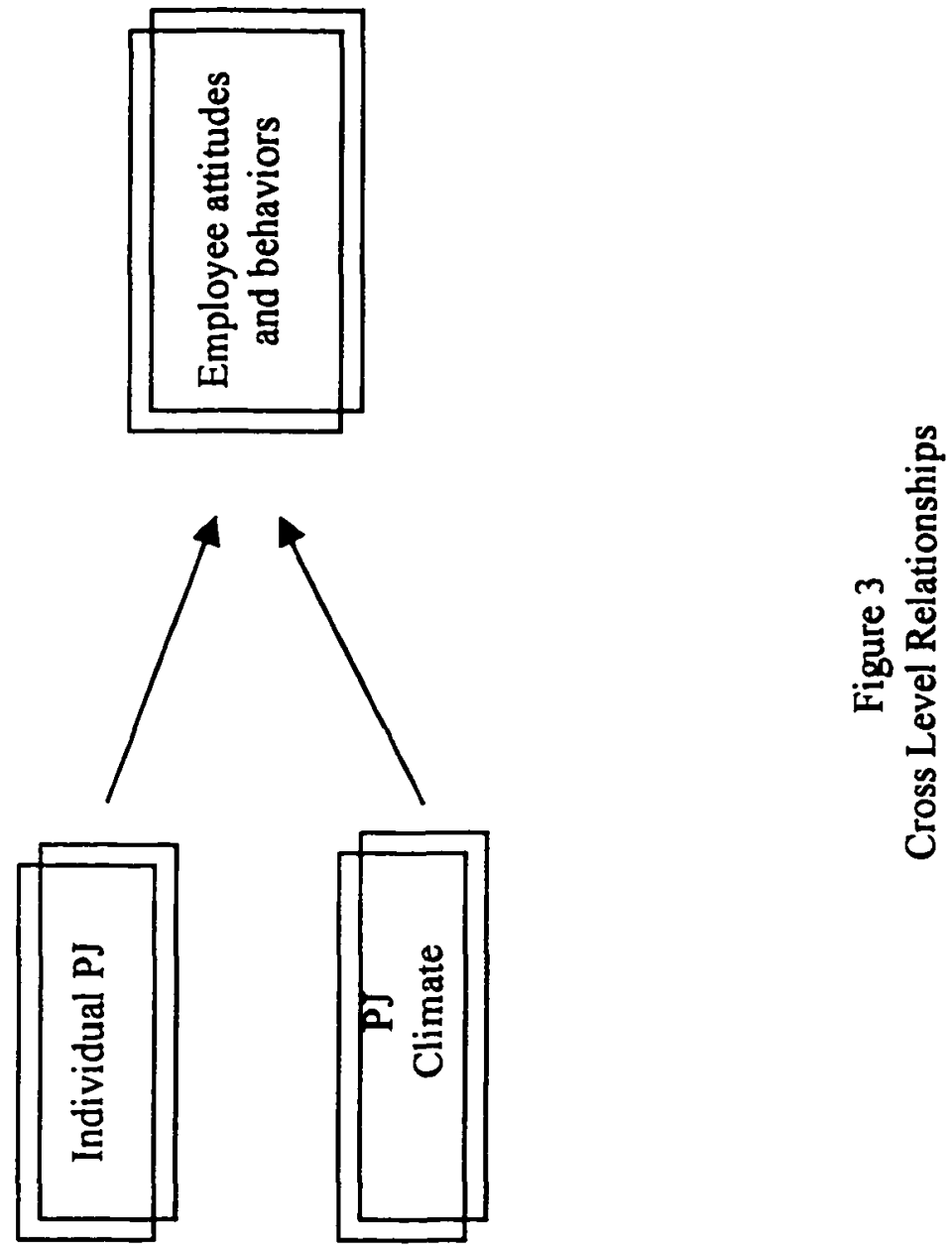
perceptions, as well as procedural justice climate, are expected to have independent effects on a variety of work-related attitudes and behaviors. The following outcomes used to test the model are described in Chapter 2: organizational commitment, citizenship behaviors, absenteeism, and turnover intentions.

\section{Summary of Remaining Chapters}

This chapter laid the groundwork for the remaining chapters of the dissertation by pointing to the lack of attention given to social context in current conceptualizations of procedural justice. Chapter 2 presents the development of the model and hypotheses concerning the individual and contextual factors proposed to independently affect individual procedural justice and procedural justice climate and the proposed consequences. Chapter 3 describes the sample, procedure, and measures used to test the hypotheses. Chapter 4 presents the results of the statistical analyses that were used to test the hypotheses. Chapter 5 identifies implications of the findings of the study for theory, research, and practice. 


\section{Chapter 2: Model Development and Hypotheses}

Factors Contributing to Individual-Level Procedural Justice Perceptions

A large body of research has investigated a variety of factors thought to contribute to the formation of individual procedural justice perceptions (see Cropanzano \& Greenberg, 1997 for a review). These factors include aspects of organizational procedures such as adequate notice (Folger, Konovsky, \& Cropanzano, 1992), two-way communication (Kim \& Mauborgne, 1993), and informational justification (Greenberg, 1990a; 1993). It appears that these 'determinants' of procedural justice are actually elements of procedural justice itself. Many of these 'determinants' closely resemble the procedural rules offered by Leventhal (1976). Leventhal (1976) suggested that in order for procedures to be fair, they must be applied consistently across individuals, free from bias, ethical, accurate, and representative of all individuals. I argue that these factors that have been regarded as antecedents in the procedural justice literature are only cues or indicators of procedural justice, rather than independent factors that cause procedural justice perceptions to develop. Thus, identifying the independent factors that contribute to the formation of individual procedural justice perceptions remains a largely unexplored area in the existing justice literature. In this dissertation I argue that perceptions of leader-member exchange quality, organizational support, and leader monitoring contribute to the formation of individual procedural justice perceptions.

\section{Leader-member exchange}

The quality of the relationship between supervisors and subordinates is expected to play a part in shaping individual procedural justice perceptions. As noted earlier, the 
self-interest explanation for procedural justice holds that, when making procedural justice evaluations, individuals consider the long-term relationship with the organization; yet, no empirical research has examined whether perceptions of the quality of the dynamic relationship between supervisors and subordinates affect subordinates' procedural justice perceptions. Research has indicated that roughly ninety percent of all work groups contain significant variance in the types of supervisor-subordinate relationships represented in them (Dansereau, Graen, \& Haga, 1975); thus, supervisors have the same type of relationship with each of their subordinates only about ten percent of the time. Further, these relationships have been found to be relatively stable over time (Liden, Sparrowe, \& Wayne, 1997).

Supervisor-subordinate relationships have been explored in the leader-member exchange (LMX) literature (Graen \& Scandura, 1987). The central idea behind LMX is that, within work groups, different kinds of relationships are formed between supervisors and subordinates. Low LMX ("out-group") relationships involve those exchanges limited to the employment contract or job description. High LMX ("in-group") relationships extend beyond the job description and are thought to result in more positive consequences for both supervisors and subordinates. Specifically, high LMX relationships have been found to predict subordinates' organizational commitment (Major, Kozlowski, Chao, \& Gardner, 1995), job satisfaction (Dansereau et al., 1975), supervisor satisfaction (Green et al., 1996), and organizational citizenship behaviors (Settoon, Bennett, \& Liden, 1996). 
Some research has begun to investigate the relationship between LMX and the interpretation of organizational events. Kozlowski and Doherty (1989) found that the nature of interactions between leaders and subordinates mediates and structures subordinate interpretations of organizational practices and events. Specifically, subordinates with high-quality supervisor relationships held perceptions more similar to those of their supervisor than subordinates with low-quality supervisor relationships.

Although the relationship between LMX and procedural justice perceptions has not been explicitly tested, it is plausible that supervisor relationships affect employee perceptions of procedural justice. Indeed, it has been suggested that, due to the relative advantage of high LMX relationships, members of low LMX relationships are likely to hold negative perceptions of procedural justice due to feelings of resentment (Yukl, 1989) or perceptions of being treated as a second-class citizen (Bass, 1990). Conversely, it has been recognized that "a good relationship with authorities promotes feelings of procedural faimess" (Tyler \& Lind, 1992, p. 158).

Hypothesis 1: Subordinates' perceptions of the quality of the exchange relationship with their supervisors will be positively related to subordinates' perceptions of procedural justice.

\section{Perceived organizational support}

Hypothesis 1 proposes that subordinate perceptions of the exchange relationship between subordinates and supervisors will affect perceptions of procedural justice. It is conceivable that subordinate perceptions of their relationships with the organization will affect perceptions of procedural justice as well. Indeed, employee-organization 
relationships have been regarded as distinct from employee-supervisor relationships (Becker, Billings, Eveleth, \& Gilbert, 1996; Settoon, et al., 1996; Tsui, Pearce, Porter, \& Hite, 1995; Wayne, Shore, \& Liden, 1997). These employee-organization relationships are thought to be so pervasive that they have been described by the concept of psychological ownership (Dirks, Cummings, \& Pierce, 1996). Because individuals feel a sense of "psychological ownership" for their organization, they do not distinguish between the self and one's possessions (in this case the organization). Thus, since the distinction between the organization and the self is blurred, it follows that when the organization treats the individual well, the individual in turn will evaluate the organization's practices well. The reverse situation in which the employee is not treated well by the organization has been examined in the psychological contract literature (Rousseau \& McLean Parks, 1992). Psychological contracts have been described as expectations concerning the reciprocal obligations comprising employee-organization exchange relationships (Morrison \& Robinson, 1997). When the employee perceives that this psychological contract has been violated by the organization, the employee is thought to develop negative procedural justice judgments by considering how the organization treats the employee (Morrison \& Robinson, 1997).

The idea of an exchange relationship between individuals and organizations has been explored further in the perceived organizational support (POS; Eisenberger, Huntington, Hutchison, \& Sowa, 1986) literature. POS is generally defined as employee perceptions of the degree to which an organization takes care of its employees. Most of the work on organizational support has been conducted by Eisenberger and colleagues 
(e.g., Eisenberger et al., 1986; Eisenberger, Fasolo, \& Davis-LaMastro, 1990).

Eisenberger et al. (1986) suggest that employee perceptions of organizational support are based on individuals' beliefs concerning the extent to which the organization values their contributions and cares about their well-being. Employees form these beliefs in order to meet needs for approval, affiliation, and esteem, as well as to estimate organizational readiness to compensate their increased effort with greater rewards. In research that followed, Eisenberger et al. (1990) found that organizational support was negatively related to absenteeism and positively related to employee conscientiousness in carrying out conventional job responsibilities. They also found that employees who perceived organizational support to be high reported stronger feelings of affiliation and loyalty, as well as expectations that high performance would produce material and social rewards (Eisenberger et al., 1990). In all, research on organizational support has found that employees who perceive their employer to be highly supportive will (1) more often interpret organizational gains and losses as their own, and (2) adopt organizational values and norms as their own (Eisenberger et al., 1990). Further, such employees are thought to trust the long-term fairness of organizations to recompense extrarole performance and to fulfill obligations in rewarding positive efforts (Organ \& Konovsky, 1989).

In summary, the literature on perceived organizational support can be used to suggest that employees who perceive their organization to be supportive will develop evaluation biases when assessing organizational practices. Specifically, employees who exhibit a high degree of POS should evaluate organizational procedures as being fair to a 
greater extent than those employees who exhibit a low degree of POS. As with the relationship between LMX and procedural justice, the relationship of POS to procedural justice is consistent with the self-interest model. That is, when making procedural justice evaluations, individuals consider the long-term relationship with the organization (i.e., through the degree of support the organization has exhibited).

Hypothesis 2: Subordinates' perceptions of organizational support will be positively related to subordinates' perceptions of procedural justice.

\section{Leader monitoring}

Another variable expected to influence subordinates' judgments of procedural justice is leader monitoring. Leader monitoring involves supervisors obtaining information about their subordinates' performance through observation, informal discussions, and formal meetings (Niehoff \& Moorman, 1993). Leader monitoring is thought to affect subordinates' perceptions of procedural justice in three ways. First, obtaining information about subordinates' performance can increase the likelihood that subordinates view the leader as one who bases decisions on accurate information (Leventhal's (1976) accuracy rule of procedural justice; Niehoff \& Moorman, 1993). Second, leader monitoring gives the leader a broad knowledge base from which to make unbiased decisions (Leventhal's (1976) bias suppression rule of procedural justice; Niehoff \& Moorman, 1993). Third, leader monitoring provides the opportunity to make decisions that are consistent across employees and over time (Leventhal's (1976) consistency rule of procedural justice; Niehoff \& Moorman, 1993). Niehoff and Moorman (1993) found that three methods of leader monitoring (observation, informal 
discussions, and formal meetings) were positively associated with subordinates' perceptions of procedural justice. The authors explained their findings by suggesting that leader monitoring provides subordinates with behavioral evidence that their supervisors value procedural faimess.

Hypothesis 3: Subordinates' perceptions of leader monitoring will be positively related to subordinates' perceptions of procedural justice.

\section{Procedural Justice Climate}

In order to argue for the existence of procedural justice climate, it is necessary to first provide evidence that work group members can be expected to hold homogeneous perceptions. Three explanations have been offered for the formation of homogeneous perceptions. Specifically, work group climates are thought to develop from 1) social interaction leading to shared meanings (symbolic interaction approach), 2) attraction/selection/attrition leading to homogeneity (ASA approach), and 3) mere exposure to the same policies, practices, and procedures (Schneider \& Reichers, 1983). Each of these explanations will be explored in the following sections that identify factors contributing to procedural justice climate (i.e., how individuals come to agree on shared perceptions of procedural justice).

Factors Contributing to Procedural Justice Climate

\section{Work group cohesion}

It has been argued that since meanings arise out of social interactions with others and since members of the same group are more likely to interact with each other than members of other groups, different groups within the organization will each hold shared 
perceptions concerning the policies, practices, and procedures that get rewarded, supported, and expected in the organization (i.e., the symbolic interaction explanation for climate development; Rentsch, 1990; Schneider \& Reichers, 1983). It follows that different climates may be seen throughout a single organization. Indeed, Rentsch (1990) found that employees who interacted with each other had similar interpretations of organizational events and employees of different interaction groups attached qualitatively different meanings to the same organizational events. Further, the group processes operating within each work group (Shaw, 1981) are expected to exert an effect on the development of procedural justice climate.

For organizations with clearly defined work groups composed of interdependent members, one of the more salient group processes operating is work group cohesion (Shaw, 1981). Cohesion may be defined as the extent to which group members are attracted to the group, strongly desire to remain in the group, and mutually influence one another (Organ \& Hamner, 1982). The classic works of Sherif (1936) and Asch (1956) laid the groundwork for a substantial amount of empirical research documenting the role of group norms and cohesion in shaping individuals' attitudes, judgments, and behaviors. This research has found that members of cohesive work groups enjoy better communication within the group, more positive evaluations of group members, and a stronger group influence (Cartwright \& Zander, 1968). These groups are also characterized by a strong level of conformity to group norms (Goodman, Ravlin, \& Schminke, 1987; Shaw, 1981) that often affect group performance (Miesing \& Preble, 1985). Group members control and direct members' behaviors and group members 
generally exhibit a high level of agreement with the rest of the group (Shaw, 1981). The basis for this agreement rests on the fact that in cohesive groups, group members identify with the group to such an extent that individual group members' self-interests are suppressed (Janis \& Mann, 1977).

A parallel argument for the existence of shared climate perceptions within cohesive work groups may be seen in the collective sense making literature (Weick, 1992). Collective sense making involves the formation of group interpretations of ambiguous stimuli. Through the process of collective sense making, individuals collectively develop shared perceptions of reality (Weick, 1992). Thus, collective sense making is thought to minimize within work group variance as common beliefs and frames of reference develop. The development of these shared beliefs and frames of reference is thought to be greatest in work groups with a high degree of cohesion (House et al., 1995).

The preceding discussion has argued for the tendency of cohesive work groups to be characterized by a high degree of agreement in their work group perceptions. In this dissertation I offer, more specifically, that cohesive groups should agree on procedural justice perceptions. Social identity theory will be used to explain this association. The theory suggests that when people join groups, they view the group as better than other groups because they are motivated to improve their own self-image (Tajfel, 1981). In addition, after joining groups, individuals begin to develop perceptions that their group deserves to be treated fairly (Brown, 1986). Just as individuals are motivated to have an enhanced self-image, they are also motivated to have an enhanced 
social identity. Thus, it follows that fair treatment to the group would be viewed to be just as important to the individual as fair treatment to the individual. Although little research has examined procedural justice in terms of its social context, Tyler and Lind (1992) have argued that a procedural justice violation against one member of a work group may be interpreted as a violation against the entire work group. It may be argued that such a violation would be more likely to be interpreted as against the entire group if the group was a cohesive one, since cohesive group members tend to identify more strongly with the group. Thus, work group cohesion taps the degree to which social identity takes hold of the group members.

Hypothesis 4: The greater the level of work group cohesion, the greater the agreement of procedural justice climate.

\section{Work group demography}

Another variable posited to influence procedural justice climate includes work group demography. Schneider's (1987) Attraction - Selection - Attrition (ASA) model has been used to explain group similarity. Stemming from interactional psychology, the ASA model suggests that work units tend to evolve toward a state of interpersonal homogeneity (Schneider, 1987). This model refutes the assumption that individuals are randomly distributed across work units. Instead, range restriction results from the attraction and selection of individuals into work units and the attrition of dissimilar individuals. The ASA framework further postulates that given the similarity of individuals within work groups, it can be reasonably expected that stimuli in the work 
unit will be perceived similarly by the people there (e.g., people will attach the same meaning to an organizational event; Schneider \& Bowen, 1985).

One way this framework has been operationalized involves similarity in demographic characteristics examined in the work group demography (Jackson, Brett, Sessa, Cooper, Julin, \& Peyronnin, 1991) or "relational demography" (Tsui, Egan, \& OReilly, 1992) literature. Similarity in demographic characteristics has been found to be associated with increased attraction to group members and similarity in group perceptions (Tsui et al., 1992). Also, Jackson et al. (1991) found that dissimilar group members were more likely to withdraw from the work group.

To summarize, similarity of work group members is thought to be associated with a high level of agreement among work group members. The underlying mechanism for this work group agreement is believed to stem from a "perceived identity of interests" (Tsui, 1994). Specifically, the perception of similarity between one's self and other work group members evokes the perception of a common set of interests and a depersonalization of one's self-interests.

The preceding discussion has argued for the tendency of work groups composed of demographically similar employees to be characterized by a high degree of agreement in their work group perceptions. In this dissertation I offer, more precisely, that demographically similar work groups should agree on procedural justice perceptions. Being in a work group with others who are similar to oneself should cause procedural justice violations against a demographically similar member of the group to be regarded as a violation against the self, since the group member and the individual are similar. 
Similar group members may come to expect that procedural justice violations against one individual may later be extended to the rest of the group, given the likeness of the group members. Members may think that if such a violation could happen to a similar group member, it could happen to them as well.

A parallel argument for the interpretation of organizational events being influenced by similar others may be seen in the consumer behavior literature (Peter \& Olson, 1993). Borrowing from the sociology literature on subcultures (i.e., groups of people who share values) and the psychology literature on behavioral modeling, marketers use demographic segmentation as a way of marketing products based on the demographic composition of groups. The idea behind this technique is that if an individual views a demographically similar individual in a media presentation as having a certain need or being afflicted by a certain condition, the similar individual watching the presentation should perceive that he/she shares this need or is afflicted with this same condition. Likewise, because the distinction between the self and the demographically similar work group is blurred, similar individuals are expected to interpret procedural justice issues (e.g., a justice violation against a demographically similar work group member) in a similar manner.

Hypothesis 5: The greater the demographic similarity of the work group, the greater the agreement of procedural justice climate.

Visibility of supervisors in demonstrating procedural justice

The third way that work group climates are thought to develop is from subordinates' perceptions of how visible the supervisor is in procedural justice 
implementation. Thus, climates are likely to develop in work groups composed of individuals sharing a supervisor who exposes them to the same policies, practices, and procedures (i.e., the mere exposure explanation for climate development). To the extent that supervisors implement organizational procedures, enforce organizational policies, and act as "deliverers" of justice in organizations, individuals working under the same supervisor (e.g., those in a work group) should hold uniform procedural justice perceptions. Supervisors behave as "climate engineers" as they shape the meaning employees attribute to organizational practices (Dansereau \& Alutto, 1990). Kozlowski \& Doherty (1989) have recognized the importance of the supervisor in shaping employee perceptions:

The leadership behaviors of immediate supervisors are likely to be salient features and to be interpreted as representative of more molar organizational processes. Even features, events, and processes occurring at higher levels are likely to be mediated by local leadership behaviors, given that an individual's immediate supervisor is the most salient, tangible representative of management actions, policies, and procedures. Thus, the nature and quality of interactions with supervisors may be a key filter in the interpretations that provide the bases for subordinates' climate perceptions" (p. 547).

Hypothesis 6: The greater the aggregate level of work group members' perceptions of the visibility of supervisors in demonstrating procedural justice, the greater the agreement of procedural justice climate.

\section{Shared support perceptions}

Hypothesis 3 stated that individuals' perceptions of organizational support will be positively related to individuals' perceptions of procedural justice. It is conceivable that group perceptions of the support given by the organization will affect procedural justice 
climate as well. As noted earlier, perceived organizational support (POS; Eisenberger et al., 1986) is defined as employee perceptions of the extent to which organizations "take care" of their employees. Although POS has been operationalized as an individual-level variable, it is conceivable that people in groups also form perceptions about the degree to which the organization supports them. The variable that taps these perceptions will be termed "shared support perceptions" in this dissertation. There is evidence that, just as work groups contain significant variance in the types of supervisor-subordinate relationships represented in them (Dansereau et al., 1975), organizations contain significant variance in the treatment of the work groups as well (e.g., Pfeffer \& Salancik, 1978). Drawing from the argument for a link between POS and individual procedural perceptions, it may be argued that when making group procedural justice evaluations, group members consider the group's long-term relationship with the organization (i.e., through the degree of support the organization has exhibited). Thus, similar to the selfinterest explanation for individuals's evaluations of procedural faimess, a group selfinterest model may account for group's evaluations of procedural faimess. Groups that perceive they are advantaged as a group with regard to receiving support from the organization should evaluate the faimess of the organization's policies and decisions more favorably than groups that do not perceive this support. Further, group members are expected to exhibit consensus on these procedural justice perceptions since they consider how the organization treats their work group as a whole. 
Hypothesis 7: The greater the aggregate level of work group members' perceptions of organizational support, the greater the agreement of procedural justice climate.

In summary, with regard to individual and group factors that contribute to procedural justice, I expect there will simultaneously be differences both within groups and between groups. There will be within group differences in procedural justice perceptions due to perceptions of leader-member exchange quality, perceptions of organizational support, and leader monitoring. There will be between group differences in procedural justice perceptions due to consensus created through work group demographic similarity, cohesion, the visibility of supervisors in demonstrating procedural justice, and shared support perceptions.

\section{Consequences of Procedural Justice Perceptions}

I suggest that the consequences of procedural justice perceptions may be best understood by considering both individual perceptions as well as procedural justice climate. A growing body of research has supported the positive relationship of individual procedural justice perceptions to both organizational commitment (e.g., Folger \& Konovsky, 1989; Konovsky et al., 1987; McFarlin \& Sweeney, 1992) and organizational citizenship behaviors (Moorman, 1991; Niehoff \& Moorman, 1993). I argue that procedural justice climate will contribute incremental variance to these consequences as well. Further, I borrow from the literature indicating that contextual factors can account for individuals' decisions to withdraw from work (e.g., Abelson, 1993; Markham \& McKee, 1995). Specifically, the model proposes that procedural 
justice climate exhibits a negative relationship with the demonsiration of withdrawal behaviors. Each of these consequences will be considered below.

Consequences of Individual Procedural Justice Perceptions

\section{Organizational commitment}

The relationship of procedural justice to other work attitudes has been widely addressed in the justice literature. The work attitude that consistently is best predicted by procedural justice is organizational commitment (e.g., Folger \& Konovsky, 1989; Konovsky et al., 1987; McFarlin \& Sweeney, 1992). Social exchange theory (Blau, 1964) has been offered as the mechanism through which procedural justice affects organizational commitment. Blau (1964) discussed two types of exchanges that exist in organizations: economic (that which is specified in the job description or employment contract) and social. Social exchange concerns a relationship that exists between an employee and employer independent of the job description. It is informally agreed upon that if the employer provides non-instrumental benefits to the employee (e.g., procedural justice), the employee will reciprocate by exhibiting organizational commitment.

Hypothesis 8: Employee perceptions of procedural justice will be positively related to perceptions of organizational commitment.

\section{Organizational citizenship behaviors}

Investigations of the relationship between individual-level procedural justice perceptions and performance have generally produced mixed or nonsignificant results. However, one component of performance, organizational citizenship behavior (OCB; Organ, 1990), has been found to be related to perceptions of procedural justice. OCB 
may be defined as helping behavior directed toward one's co-workers or the organization that is discretionary and not required by one's job description. Although job satisfaction has been traditionally thought to predict the demonstration of OCBs, Moorman (1991) found that once procedural justice perceptions were controlled for, job satisfaction no longer predicted OCBs. Similar to the relationship between procedural justice and organizational commitment, Moorman explained his findings in terms of social exchange theory (Blau, 1964): Employees who perceive the organization's procedures are fair will reciprocate by engaging in OCBs. Conversely, individuals who perceive the organization's procedures to be unfair will refrain from engaging in this form of discretionary behavior. Further, Organ (1990) has argued that unfairness not only reduces OCBS, but also changes the employment contract from relational to simply one of economic exchange.

Hypothesis 9: Employee perceptions of procedural justice will be positively related to supervisor ratings of organizational citizenship behaviors.

\section{Consequences of Procedural Justice Climate}

\section{Withdrawal behaviors}

The consequences of procedural justice climate include two withdrawal behaviors: absenteeism and turnover. Whereas traditional withdrawal models point to affective explanations for withdrawal behaviors (e.g., job satisfaction), some research has found that group factors can account for individuals' desires to withdraw from work through absenteeism (Markham \& McKee, 1995; Mathieu \& Kohler, 1990; Nicholson \& 
Johns, 1985) and turnover (Abelson, 1993). Group norms and supervisors' interactions with group members help to shape "withdrawal cultures" through social information processing (SIP; Salancik \& Pfeffer, 1978). For example, through interacting with members of one's work group, employees may come to perceive that absence behavior is a legitimate behavioral response (Nicholson \& Johns, 1985) and turnover intentions are a legitimate psychological response (Abelson, 1993) to negative feelings about one's job or organization. Consistent with the group values model, one's perception of procedural justice is affected by others in one's group. Thus, other group members may provide the individual with further evidence of fair or unfair treatment and this shared cognition is likely to affect the group's rate of withdrawal from their jobs. Exactly how much individual withdrawal behavior is affected by the work group depends on the level of agreement of the work group perceptions concerning whether absence and turnover are viewed as a legitimate response to negative perceptions of procedural justice.

Other indications of the expected relationship between procedural justice climate and withdrawal behaviors pertain to work group cohesion and demographic similarity. High levels of communication have been found to be inversely associated with withdrawal behaviors (Abelson, 1993). Since high levels of communication and interaction are a characteristic of interdependent, cohesive groups, it is expected that groups with strong procedural justice climates (i.e., those with high levels of communication) will exhibit lower levels of withdrawal behaviors. Some research has indicated that cohesive groups tend to exhibit fewer withdrawal behaviors than noncohesive groups (Lott \& Lott, 1965; Shaw, 1981; Stogdill, 1972). In addition, 
homogeneous groups composed of similar group members exhibit lower levels of turnover than heterogeneous groups composed of dissimilar group members (Jackson et al., 1991). Since work group cohesion and demographic similarity have been associated with the frequency of withdrawal behaviors, it is plausible to expect that procedural justice climate will also be related to the incidence of withdrawal behaviors.

Hypothesis 10: Procedural justice climate will be negatively associated with work groups absenteeism.

Hypothesis 11: Procedural justice climate will be negatively associated with individuals' turnover intentions, beyond that explained by job satisfaction.

\section{Organizational commitment and organizational citizenship behaviors}

Similar conclusions may be drawn for variables traditionally associated with individual-level procedural justice perceptions, organizational commitment and organizational citizenship behaviors (OCBs). As noted earlier, previous research has consistently found that individual procedural justice perceptions predict levels of organizational commitment (e.8., Folger \& Konovsky, 1989; Konovsky et al., 1987; McFarlin \& Sweeney, 1992) and OCBs (Moorman, 1991; Niehoff \& Moorman, 1993). It is plausible that contextual factors will also explain some of the variance in organizational commitment and OCBs, beyond that explained by individual conceptualizations of procedural justice. Whereas social exchange theory has been used to explain why individual-level procedural justice perceptions are associated with organizational commitment and OCBs, group dynamics may be used to explain a 
relationship between procedural justice climate and organizational commitment. Group norms of procedural fairness/unfaimess and interactions among group members about procedural faimess issues are expected to affect individuals' decisions to engage in OCBs and exhibit organizational commitment.

Hypothesis 12: Procedural justice climate will be positively associated with organizational commitment, beyond that explained by individual procedural justice perceptions.

Hypothesis 13: Procedural justice climate will be positively associated with organizational citizenship behaviors, beyond that explained by individual procedural justice perceptions.

\section{Job satisfaction and intentions to turnover}

Whereas Hypothesis 11 stated that procedural justice climate will be negatively associated with individuals' tumover intentions, individual-level affective explanations for turnover are expected to contribute some of the variance in individuals' turnover intentions as well. The affective predictor linked most often to individuals' turnover intentions has been job satisfaction. Both conceptual (e.g., Mobley, 1977) and metaanalytic (Tett \& Meyer, 1993) reviews of the job satisfaction - turnover relationship have reported a consistent negative relationship. The underlying rationale for this relationship has been that individuals who feel dissatisfied with their jobs are likely to desire to withdraw from their jobs (e.g., through thinking of quitting). Thus, it is expected that a group-level (procedural justice climate) factor and an individual-level (job satisfaction) factor will explain some of the variance in individuals' turnover intentions. 
Hypothesis 14: Subordinates' perceptions of job satisfaction will be negatively related to their intentions to turnover.

\section{Summary}

To summarize, this chapter proposed a model that identifies social context factors that contribute to a procedural justice climate. This climate, in turn, is expected to influence work-related attitudes and behaviors beyond the effects of individual procedural justice considerations. A summary of the hypotheses appears in Table 1. 
Table 1

Summary of Hypotheses

Hypothesis 1: Subordinates' perceptions of the quality of the exchange relationship with their supervisors will be positively related to subordinates' perceptions of procedural justice.

Hypothesis 2: Subordinates' perceptions of organizational support will be positively related to subordinates' perceptions of procedural justice.

Hypothesis 3: Subordinates' perceptions of leader monitoring will be positively related to subordinates' perceptions of procedural justice.

Hypothesis 4: The greater the level of work group cohesion, the greater the agreement of procedural justice climate.

Hypothesis 5: The greater the demographic similarity of the work group, the greater the agreement of procedural justice climate.

Hypothesis 6: The greater the aggregate level of work group members' perceptions of the visibility of supervisors in demonstrating procedural justice, the greater the agreement of procedural justice climate.

Hypothesis 7: The greater the aggregate level of work group members' perceptions of organizational support, the greater the agreement of procedural justice climate.

Hypothesis 8: Employee perceptions of procedural justice will be positively related to perceptions of organizational commitment.

Hypothesis 9: Employee perceptions of procedural justice will be positively related to supervisor ratings of organizational citizenship behaviors.

Hypothesis 10: Procedural justice climate will be negatively associated with work group absenteeism.

Hypothesis 11: Procedural justice climate will be negatively associated with individuals' turnover intentions, beyond that explained by job satisfaction.

Hypothesis 12: Procedural justice climate will be positively associated with organizational commitment, beyond that explained by individual procedural justice perceptions.

Hypothesis 13: Procedural justice climate will be positively associated with organizational citizenship behaviors, beyond that explained by individual procedural justice perceptions.

Hypothesis 14: Subordinates' perceptions of job satisfaction will be negatively related to their intentions to turnover. 


\section{Chapter 3: Method}

\section{Sample}

The data used to test the hypotheses were collected from 220 employees at 34 locations of two banks in a major metropolitan area in the southeastern United States. Both banks were regional banks with roughly the same number of branches in the metropolitan area at the time of the study. The banks had similar levels of financial profitability. The branches of each of the banks were roughly the same size, with the exception of some smaller branches of one of the banks located in grocery stores.

In each bank, branches were conceptualized as consisting of formally defined work groups of interdependent individuals at the same level of the organizational hierarchy who performed similar tasks and shared a supervisor. Two branches from each bank did not participate due to high turnover of employees and a recent reassignment of branch managers. Two other branches in the first bank did not participate because they contained fewer than three individuals. Group size ranged from 3 to 14 individuals. The average group size was 6.1 employees. In the 16 branches representing the first bank, $87 \%$ were female and $66 \%$ were white. The average age was 30 years and the average tenure was 4.7 years. In the 18 branches representing the second bank, $84 \%$ were female and $64 \%$ were white. The average age was 32.9 years and the average tenure was 6.9 years. The two banks did not differ significantly from one another in terms of employee demographics, except for education level. In the first bank, $10 \%$ were college graduates, compared with $28 \%$ in the second bank. The second bank had been making a deliberate effort to increase the qualifications of its staff. Although this is a statistically 
significant difference, there is no reason to suspect this difference would affect the results since the hypothesis pertaining to education level (Hypothesis 5) concerns heterogeneity within the group and not absolute levels of education. Each of the current study's hypotheses were initially tested in each bank's data separately; no significant differences between the two banks' results were detected.

\section{Procedure}

Most previous organizational justice research and work group climate research has used surveys to measure perceptions and climate without directly measuring how employees interpret their work environments. In such studies, researchers attach their own meanings to the findings. How employees form perceptions and interpret events is a largely unexplored area. Thus, both qualitative and quantitative methods were used to assess employees' affective reactions to the organization's policies, practices, and procedures. Before the surveys were administered, semi-structured interviews were conducted with five randomly selected work groups to examine whether the concept of procedural justice climate was tenable. In asking the employees questions, the procedure used by Schneider, Wheeler, and Cox (1992) was followed. This procedure begins with general questions to initiate discussion (e.g., Describe the climate of this branch and the role of faimess in it) and then subsequent questions become more specific (e.g., Could you tell me the kinds of things that happen that lead you to the conclusion that your work group feels it's treated fairly/unfairly?).

Identifying the themes that emerged consistently in the group interviews served several purposes. First, asking participants how they make procedural justice 
evaluations (e.g., Who do you think of when you consider whether a procedure is fair?) provided a check on the use of both individual and group quantitative measures of procedural justice. Second, asking participants about the meaning they attach to organizational events provided a validity check on whether work group members agreed on how they interpret various organizational procedures (i.e., the existence of procedural justice climate within work groups). Specifically, employees were asked to describe several organizational events or procedures that came to mind when evaluating the faimess of organizational practices. Third, asking participants what makes a procedure fair helped to determine if there were any overlooked issues that could have been added to the quantitative procedural justice measures.

After the semi-structured interviews were completed, surveys were administered at each of the banks' branches. The employees and supervisors of each of the 34 participating work groups completed surveys, yielding an overall response rate of $100 \%$. A coding system was devised to match branch employee surveys with those of their supervisor. Employees were assured of their anonymity and were told that the number on their survey was for matching purposes only and that no individual employee could be identified.

\section{Employee Survey Measures}

All scales are based on responses to items using a five-point scale. The scale items were averaged and coded such that a high score indicates a high level of the focal measure. Cronbach's alpha was computed on all measures to determine if they met the minimum threshold of .70 recommended by Nunnally (1978) to indicate reliability. A 
complete list of survey items grouped by variable names appears in Appendix A. The employee and supervisor surveys appear in Appendices B and C.

Individual level variables

Leader-member exchange quality. Employees' perceptions of the quality of their relationship with their supervisors (LMX) were measured using Scandura and Graen's (1984) seven-item $(\alpha=.90)$ Leader-Member Exchange Scale. As this scale taps individual perceptions about their supervisors, items were worded to reflect the individual level of analysis. Sample items include the following: "I know where I stand...I usually know how satisfied my supervisor is with what I do"; "My supervisor recognizes my potential"; "I have an effective working relationship with my supervisor."

Perceived organizational support. Perceived organizational support (POS) was measured using eight items $(\alpha=.90)$ from Eisenberger et al.'s (1986) Survey of Perceived Organizational Support. This survey measures employee judgments of the organization and actions it takes that affect employees' well-being. As this scale taps individual perceptions about whether the organization supports them, items were worded to reflect the individual level of analysis. Sample items include the following: [This organization] . . . "strongly considers my goals and values;" "is willing to extend itself to help me do my job to the best of my ability;" "takes pride in my accomplishments at work."

Leader monitoring. Employee perceptions of the extent to which their supervisors monitor their work were assessed by Niehoff and Moorman's (1993) fiveitem $(\alpha=.81)$ leader observation scale. Sample items include the following: [My 
supervisor frequently .. .] "Checks to see if I am working efficiently"; "Watches me as I work"; "Carefully examines the work I have completed."

Individual procedural justice. Nine items $(\alpha=.83)$ derived from Greenberg (1986) were used to measure employee perceptions of the faimess of the procedures used to arrive at decisions. These items reflect Leventhal's (1976) procedural rules. As this scale taps individual perceptions about the organization's use of procedural rules, items were worded to reflect the individual level of analysis. Sample items include the following: [At this organization] ... "consistent rules and procedures are used when making decisions that affect me;" "input from me is sought prior to making a decision;" "personal motives and biases influence decisions that affect me" (reverse coded).

Organizational commitment. Employee perceptions of their attachment to the organization were measured using nine items $(\alpha=.87)$ from the Organizational Commitment Questionnaire (Mowday, Steers, \& Porter, 1979). This individual-level scale assesses the degree to which individuals desire to preserve organizational membership and to exert effort, as well as their acceptance of organizational goals and values as their own (Mowday, Steers, \& Porter, 1982; Angle \& Perry, 1986). Sample items include the following: "I talk up this organization to my friends as a great organization to work for;" "This organization inspires the very best in me in terms of job performance;" "For me, this is the best of all possible organizations for which to work."

Turnover intentions. Employee judgments of their intentions to turnover were measured using six items from the Organizational Commitment Questionnaire $(\alpha=.75)$. Previous research has indicated that these negatively-worded items tap an intent-to-quit 
factor (Carsten \& Spector, 1987; Williams \& Hazer, 1986). Sample items include the following: "It would take very little change in my present circumstances to cause me to leave this organization"; "I could just as well be working for a different organization as long as the type of work was similar"; "Deciding to work for this organization was a definite mistake on my part."

Job satisfaction. The extent to which subordinates are satisfied with their jobs was assessed using a three-item $(\alpha=.81)$ global job satisfaction scale adapted from Hackman and Oldham (1975). Sample items include the following: "All things considered, I am satisfied with my job."; "I like my job"; "I am generally satisfied with the work I do in this job."

Group level variables

Work group cohesion. Work group cohesion may be defined as the extent to which group members are attracted to the group, strongly desire to remain in the group, and mutually influence one another (Organ \& Hamner, 1982). Eight items $(\alpha=.89)$ from Dobbins and Zaccaro's (1986) scale were adapted to tap employee perceptions of work group cohesion. The items were adapted to reflect the group level of analysis. Sample items include the following: [As a whole, the people in my work group feel that ... ] "We are really a part of our work group"; "We will readily defend each other from criticism from outsiders"; "Our work group is a close one." Within each work group, responses to this measure were aggregated to generate a group-level cohesion measure.

Work group heterogeneity. Five demographic characteristics were obtained from the questionnaires: age, tenure, gender, race, and the highest level of education attained. 
Consistent with previous research on work group heterogeneity (e.g., Jackson et al., 1991), two kinds of heterogeneity indices were computed. For interval variables (age and tenure), the coefficient of variation (group standard deviation of a demographic variable divided by group mean of a demographic variable) was computed. For categorical variables (gender, race, education), Blau's (1997) index of heterogeneity was computed. This index is computed by the following equation: Heterogeneity $=\left(1-\Sigma p_{i}{ }^{2}\right)$, where $\mathrm{p}$ is the proportion of group members belonging to a demographic category and $\mathrm{i}$ is the number of different categories). The index ranges from 0 (if all group members are the same demographic attribute) to 1 .

Visibility of supervisors in demonstrating procedural justice. A scale that taps group perceptions of the visibility of supervisors in demonstrating procedural justice was created for this study. Sample items $(\alpha=.91)$ include the following: "Our work group has the opportunity to observe our supervisor implementing organizational policies in our work group"; "Our work group sees our supervisor as a key administrator of this organization's policies, practices, and procedures." Within each work group, responses to this measure were aggregated to generate a group-level measure.

Shared support perceptions. Shared support perceptions were measured using eight items $(\alpha=.92)$ adapted from Eisenberger et al.'s (1986) Survey of Perceived Organizational Support. This survey measures employee judgments of the organization and actions it takes that affect employees' well-being. As this scale taps individuals' perceptions about whether the organization supports them, items were adapted to reflect the group level of analysis. Sample items include the following: [This organization] ... 
"strongly considers our work group's goals and values;" "is willing to extend itself to help our group do its job to the best of its ability;" "takes pride in my work group's accomplishments." Within each work group, responses to this measure were aggregated to generate a group-level measure.

Procedural justice climate. In order for multi-level analyses to be conducted, the level at which individual responses are collected should make conceptual sense (Schneider, 1990). Thus, respondents were provided with the frame of reference appropriate for the level of analysis for which the procedural justice climate data was used (i.e., the work group). To obtain a work group-level measure of procedural justice climate, employees responded to nine items $(\alpha=.90)$ modified from Greenberg's (1986) individual procedural justice scale to include a work group reference. Sample items include the following: "As a whole, the people in my work group feel that around here . . consistent rules and procedures are used when making decisions; our input is obtained prior to making decisions; accurate information is used to make decisions").

Procedural justice climate agreement. James, Demaree, and Wolf's $(1984 ; 1993)$ interrater agreement index $\left(\underline{r}_{w_{2}}\right)$ was computed on the procedural justice climate measure in order to provide a measure of procedural justice climate agreement within work groups. The mean for this agreement index and the means for the agreement indices of the other group level measures are reported in the Results section.

Archival data. Absenteeism data were obtained from one of the bank's archival records. The average number of hours employees were absent from their jobs in the last 9 months was calculated for each branch. Only full-time, non-supervisory employees 
were included in these calculations. It was not possible to obtain absenteeism data from the second bank. Thus, the sample size for the analyses involving work group absenteeism was limited to eighteen work groups.

\section{Supervisor Survey Measures}

Individual level variables

Organizational citizenship behaviors. Supervisors assessed the extent to which each of their subordinates engage in helping behaviors directed toward the organization and other co-workers. Seven items from Williams and Anderson's (1991) scale were used $(\alpha=.84)$. Sample items include the following: "This employee helps others who have heavy workloads"; "This employee assists me (the supervisor) with my work when not asked"; "This employee goes out of his/her way to help new employees." 


\section{Chapter 4: Analyses and Results}

This chapter reports the findings of the study. First, the findings of the work group interviews are described. Next, the statistical analyses used to test the hypotheses are presented. Finally, the results of the individual, group, and multi-level hypothesis tests are reported.

\section{Work Group Interviews}

First, when asked what contributes to a procedure being evaluated as fair, employees responded that both individual- and group-level evaluations contribute to their perceptions. Several employees explained that because of their close proximity to one another, it is easy to observe their supervisor exhibiting various degrees of procedural justice to their co-workers. They said that when they witness an injustice against one group member, they interpret it as a violation against the entire group because their jobs are so similar. This provided a check on the use of both individual and group quantitative measures of procedural justice on the questionnaire.

Second, employees were asked about what organizational events and practices mean to them. Group members tended to agree with each other about how they interpreted various events or processes that group members identified. When one group member would talk about a particular procedural justice issue (e.g., the promotion system), the co-workers generally responded by offering more evidence to support the group member's idea or by displaying affirmative nods. This provided a validity check as employees within each work group largely agreed on how they interpreted various 
organizational procedures (i.e., the existence of procedural justice climate within work groups).

Finally, the work group interviews and the open-ended comments written at the end of the surveys provided evidence of the salience of procedural justice to the work groups in the sample. Excerpts from these comments appear below:

I feel that the bank may not be sensitive to employee concerns. I also feel that personal biases too often influence decisions.

Better rules would benefit the employees of this bank.

I feel like managers don't listen unless they feel like it.

Not all decisions that affect people in my position are looked at from my perspective.

In our branch, a lot of favoritism is shown to one individual member and, in turn, that brings down the morale of the rest of the group.

I feel our manager should show more concern. She says, "I am the boss, you do what I say."

Things have happened at our branch and the manager will question other employees to find out their input before discussing the situation with a certain employee. I don't think other employees should be questioned about their co-workers. I think it should be between the manager and that certain employee to work out.

I do not feel that everyone is treated fairly at this branch. It all depends on what mood the manager is in when you need something.

Some employee situations have not been handled according to the bank's policies, I believe.

The promotion system is not fair. 
In sum, the work group interviews provided evidence of (1) the contribution of both individual and group factors to the development of employees' procedural justice perceptions, (2) the extent to which employees agreed within work groups on how they interpreted organizational practices, and (3) the salience of procedural justice issues to the work groups.

\section{Confirmatory Factor Analysis (CFA)}

Since many of the variables collected from the questionnaire were expected to be intercorrelated and many of them were collected from the same source (i.e., leadermember exchange, perceived organizational support, leader monitoring, individual procedural justice, organizational commitment, job satisfaction, and turnover intentions), a confirmatory factor analysis using LISREL 8 (Joreskog \& Sorbom, 1993) was conducted to determine if the measures were empirically distinct. A superior fit for a seven factor model, as compared to a one factor 'common method' model (cf. Podsakoff \& Organ, 1986), would suggest that common method variance alone does not explain the results, although it cannot be conclusively ruled out (McFarlin \& Sweeney, 1992; Oswald, Mossholder, \& Harris, 1994).

Using the approach outlined by Williams and Hazer (1986), indicators were created for each of the seven latent variables by constructing item parcels (West, Finch, \& Curran, 1995), which are calculated by averaging the items of each scale based on the items' factor loadings. Even models with strong theoretical support are less likely to fit when there are more than thirty indicators (Joreskog \& Sorbom, 1993). Thus, scale 
scores, rather than the forty-seven individual items, were used as indicators of the latent variables in each of the models.

Results of the confirmatory factor analysis appear in Table 2. Goodness-of-fit indices suggested by Gerbing and Anderson (1993) demonstrated that the seven factor measurement model provided a superior fit. Specifically, the Comparative fit index (CFI) of the seven factor model was .97, compared to .65 for the one factor model; the Incremental fit index (IFI) of the seven factor model was .97, compared to .65 for the one factor model. It has been suggested that theoretically proposed measurement models should also be compared with an alternative theoretically plausible model since the one factor model is generally likely to provide a poor fit (Williams \& Hazer, 1986). In light of this recommendation, the seven factor measurement model was compared with a six factor theoretically plausible model where the three procedural justice scale indicators were set to load on the leader-member exchange latent variable. This model was selected because procedural justice and leader-member exchange are often correlated and the two scales overlap conceptually. Goodness-of-fit indices indicated that the seven factor measurement model again provided a superior fit. Specifically, the Comparative fit index (CFI) of the seven factor model was .97 , compared to .85 for the six factor model; the Incremental fit index (IFI) of the seven factor model was .97 , compared to .85 for the six factor model. A $\chi^{2}$ difference statistic indicated that the seven factor model fit significantly better than the six factor model $\left(x^{2}=320.34, \mathrm{R}<\right.$ .01). Taken together, these results suggested that the self-report measures of leadermember exchange, perceived organizational support, leader monitoring, individual 
Table 2

Confirmatory Factor Analysis

on Individual Level Variables

\begin{tabular}{lccccc}
\hline & $\chi^{2}$ & df & GFI & CFI & IFI \\
\hline 7 factor model & $235.6^{* *}$ & 168 & .91 & .97 & .97 \\
1 factor model & $1097.5^{* *}$ & 174 & .64 & .65 & .65 \\
6 factor model & $555.9^{* *}$ & 189 & .78 & .85 & .85 \\
\hline
\end{tabular}

$* * \mathrm{p}<.01$ 
procedural justice, organizational commitment, job satisfaction, and turnover intentions could be examined as empirically distinct variables.

\section{Tests of Hypotheses}

Individual-level hypothesis tests

Descriptive statistics for individual level variables appear in Table 3. Four hypotheses developed in Chapter 2 involve analyses of data at the level of the individual respondent. Hypothesis 1 predicted that subordinates' perceptions of the quality of the exchange relationship with their supervisors will be positively related to subordinates' perceptions of procedural justice. Hypothesis 2 predicted that subordinates' perceptions of organizational support will be positively related to subordinates' perceptions of procedural justice. Hypothesis 3 predicted that subordinates' perceptions of leader monitoring will be positively related to subordinates' perceptions of procedural justice. Hypothesis 14 predicted that subordinates' perceptions of job satisfaction will be positively related to subordinates' intentions to turnover. The critical test of these individual-level hypotheses involved ordinary least squares (OLS) regression. The results of these analyses are reported in Table 4.

First, individual procedural justice perceptions were regressed on LMX, POS, and leader monitoring. The positive significant main effects of $\operatorname{LMX}(\beta=14, p<.01)$,

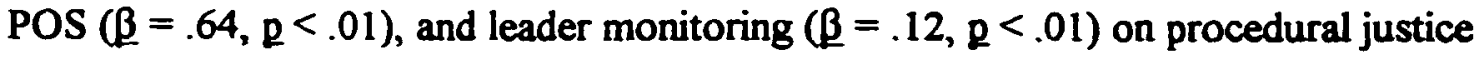
perceptions indicated support for Hypotheses 1, 2, and 3 (respectively). 
Table 3

Descriptive Statistics for

Individual Level Variables

\begin{tabular}{|c|c|c|c|c|c|c|}
\hline & Mean & SD & 1 & 2 & 3 & 4 \\
\hline 1. Individual procedural justice & 3.11 & .70 & .83 & & & \\
\hline 2. Leader member exchange & 3.80 & .78 & $.46^{* *}$ & .90 & & \\
\hline 3. Perceived organizational support & 3.37 & .81 & $.74^{* *}$ & $.42^{* *}$ & .90 & \\
\hline 4. Leader monitoring & 3.39 & .84 & $.36^{* *}$ & $.42^{* *}$ & $.29 * *$ & .81 \\
\hline
\end{tabular}

$\underline{n}=220$

${ }^{* *} \mathrm{p}<.01$

Scale alphas are reported on the diagonal. 
Table 4

Regression Analyses on

Individual Level Variables

Dependent variable

\begin{tabular}{lcc}
\hline & \multicolumn{2}{l}{ Individual procedural justice } \\
\hline Independent variables & $\underline{\mathrm{p}}$ \\
Leader Member Exchange & .14 & .01 \\
Perceived Organizational Support & .64 & .01 \\
Leader Monitoring & .12 & .01 \\
$\mathrm{R}^{2}$ & .58 & \\
$\mathrm{~F}$ & 96.73 & .01 \\
$\mathrm{n}=220$ & &
\end{tabular}

$\underline{\mathrm{n}}=\mathbf{2 2 0}$ 
Group-level hypothesis tests

Descriptive statistics for procedural justice climate agreement and its group-level predictors are shown in Table 5. Hypotheses 4 through 7 concern the prediction of procedural justice climate. These hypotheses state (respectively) that the greater the levels of work group cohesion, demographic similarity, visibility of supervisors in demonstrating procedural justice, and shared support perceptions, the greater the agreement of procedural justice climate. Before aggregating these variables to the level of the work group, within group agreement had to be demonstrated. James, Demaree, and Wolfs $(1984 ; 1993)$ interrater agreement index $\left(I_{m g}\right)$ was computed for each grouplevel variable. Within group agreement was demonstrated for procedural justice climate $\left(\underline{\mathrm{wg}}_{\mathrm{mg}}=.82\right)$, cohesion $\left(\underline{I}_{\mathrm{mg}}=.80\right)$, shared support perceptions $\left(\underline{r}_{\mathrm{mg}}=.79\right)$, and supervisor visibility in demonstrating procedural justice $\left(I_{\mathrm{wg}}=82\right)$. These indices were consistent with those found in previous work group research (e.g., Campion et al., 1993). Next, the procedure outlined by Cohen and Cohen (1983) was followed to partition the variance explained in procedural justice climate agreement into components. The procedure involved computing semipartial $R^{2}\left(\mathbf{s R}^{2}\right)$ for each group-level predictor in order to determine the proportion of variance each predictor uniquely contributed to procedural justice climate agreement, after controlling for the other group-level predictors. The results of this analysis are presented in Table 6. Based on these results, it was concluded that shared support perceptions contributed very little to procedural justice climate agreement $\left(s R^{2}=.01\right)$. Hypothesis 7 was not supported; thus, this variable was not included in the subsequent analysis. 
Table 5

Group Level Descriptive Statistics

\begin{tabular}{|c|c|c|c|c|c|c|c|c|c|c|}
\hline & Mean & SD & 1 & 2 & 3 & 4 & 5 & 6 & 7 & 8 \\
\hline 1. PJ climate agreement & .82 & .13 & . & & & & & & & \\
\hline 2. Work group cohesion & 3.84 & .48 & $.49^{* *}$ & .89 & & & & & & \\
\hline 3. Supervisor visibility & 3.86 & .49 & $.50^{* *}$ & $.53^{* *}$ & .91 & & & & & \\
\hline 4. Education heterogeneity & .46 & .17 & -.07 & .17 & .18 & . & & & & \\
\hline 5. Gender heterogeneity & .20 & .18 & .05 & .09 & .03 & -.07 & & & & \\
\hline 6. Race heterogeneity & .33 & .21 & .01 & -.13 & -.04 & -.10 & .07 & . & & \\
\hline 7. Age heterogeneity & .30 & .11 & $-.30^{*}$ & -.27 & -.21 & .17 & $-.46 * *$ & .01 & . & \\
\hline 8. Tenure heterogeneity & 1.04 & .45 & -.03 & -.04 & .19 & .25 & -.01 & $.46^{* *}$ & .30 & \\
\hline
\end{tabular}

$\underline{n}=34$

$* \mathrm{p}<.05$

$* * \mathrm{p}<.01$

Where applicable, scale alphas are reported on the diagonal. 
Table 6

$\mathbf{R}^{2}$ and $\mathbf{s} \mathbf{R}^{2}$ for Group Level Predictors

of Procedural Justice Climate Agreement

\begin{tabular}{lcc}
\hline & $\underline{\mathbf{R}^{2}}$ & $\underline{\mathbf{R}^{2}}$ \\
\hline Shared support perceptions & .07 & .01 \\
Work group cohesion & .24 & .07 \\
Supervisor visibility & .25 & .04 \\
Education, gender, race heterogeneity & .01 & .03 \\
Age, tenure heterogeneity & .10 & .01 \\
\hline
\end{tabular}

$\underline{\mathrm{n}}=34$

$\underline{R}^{2}=$ focal variable in model by itself

$\underline{\mathbf{R}^{2}}=$ total model $\underline{\mathrm{R}}^{2}$ - all variables in model except focal variable = variance uniquely explained by the focal variable total $\underline{R}^{2}=.37$ 
Preconditions of testing multi-level hypotheses

Before conducting multi-level analyses on Hypotheses 11,12, and 13, and grouplevel analyses on Hypotheses 4 through 7 and 10, it had to be established that there was within group agreement and systematic between group variance. As reported earlier, in order to empirically test the extent to which the group-level perceptions are homogeneous (i.e., the extent to which group members agree and within group variance is minimal), James et al.'s $(1984 ; 1993)$ interrater agreement index $\left(\underline{r}_{\mathrm{mg}}\right)$ was computed for the procedural justice climate measure. The mean $r_{\text {gag }}$ was .82 across the 36 work groups.

In order to empirically test whether sufficient between group variance existed to conduct a cross-level analysis, the eta coefficient ( $\eta$; James, 1982) was also computed for the procedural justice climate measure. The $\eta^{2}$ statistic provides a measure of variance explained between groups by computing the ratio of the between-groups sum of squares and the total sum of squares. The $\eta^{2}$ was $.37(\underline{F}=2.91, p<.01)$ for the procedural justice climate measure, indicating that $37 \%$ of the variance in this measure is between groups. Although there are no absolute standards concerning adequate levels of $I_{\mathrm{mg}}$ or $\eta^{2}$, results were compared with those observed in other multilevel studies and were found to be adequate (e.g., James, 1982; Mossholder, Bennett, \& Martin, in press; Thomas, Shankster, \& Mathieu, 1994).

The test of Hypotheses 4 through 6 involved ordinary least squares (OLS) regression at the group level of analysis. Procedural justice climate agreement was regressed on work group cohesion, demographic similarity, and the visibility of 
supervisors in demonstrating procedural justice. The results of these analyses appear in Table 7. The positive significant main effect of work group cohesion $(\underline{\beta}=.31, \mathrm{Q}<.05)$ and supervisor visibility $(\beta=.34, Q<.05)$ on procedural justice climate agreement indicated support for Hypotheses 4 and 6 (respectively). None of the demographic similarity indices exhibited main effects on procedural justice climate agreement; thus, Hypothesis 5 was not supported.

Since procedural justice climate perceptions were found to be homogeneous (i.e., within group variance was minimal), it was possible to proceed to test Hypothesis 10 . Hypothesis 10 predicted that procedural justice climate will be negatively related to work group absenteeism. As noted earlier, absenteeism data were available from only one of the banks in the sample. Thus, the sample size to test Hypothesis 10 was eighteen work groups. The critical test of this hypothesis involved ordinary least squares (OLS) regression at the group level of analysis. Work group absenteeism was regressed on procedural justice climate. Results of this analysis appear in Table 8. Procedural justice climate did not exhibit a significant main effect on absenteeism. Thus, Hypothesis 10 was not supported $(\underline{\beta}=-.19, \mathfrak{p}<.23)$.

Multi-level hypothesis tests

Consistent with a cross-level theory, a cross-level analysis was performed for Hypotheses 11, 12, and 13 (Rousseau, 1985). Researchers conducting cross-level analyses have a choice among three statistical techniques. First, the data can be disaggregated by assigning each lower level unit a score representing the higher level unit within which it is nested (Hofmann, 1997). Problems with this approach include (1) the 
Table 7

Regression Analyses on Group Level Predictors

of Procedural Justice Climate Agreement

Dependent variable

\begin{tabular}{lcc}
\hline & \multicolumn{2}{c}{ Procedural justice climate agreement } \\
\hline Independent variables & \multicolumn{1}{c}{$\mathbf{p}$} \\
\hline Work group cohesion & .30 & .05 \\
Supervisor visibility & .34 & .04 \\
Education heterogeneity & -.15 & .16 \\
Gender heterogeneity & -.07 & .35 \\
Race heterogeneity & .07 & .34 \\
Age heterogeneity & -.15 & .23 \\
Tenure heterogeneity & -.03 & .44 \\
\hline $\mathrm{R}^{2}$ & .37 & .05 \\
\hline F & & \\
\hline One-tailed tests are reported. & & \\
\hline
\end{tabular}


Table 8

Regression Analysis: Procedural Justice Climate

Predicted by Work Group Absence

Procedural justice climate

는

\begin{tabular}{lll}
\hline Work group absenteeism & -.19 & .23
\end{tabular}

$\underline{\mathrm{n}}=18$

One-tailed test. 
difficulty of satisfying the independence of observations assumptions in traditional statistical methods and (2) the evaluation of the effect of higher level units based on the number of lower level of units (Byrk \& Raudenbush, 1992). Second, lower level units can be aggregated and relationships at the aggregate level can be examined. This approach, however, disregards potentially meaningful lower level variance (Hofmann, 1997).

A third approach, hierarchical linear modeling (HLM), overcomes the problems of the previous approaches. HLM has been used frequently in education research and has recently been given attention by organizational researchers interested in multi-level analyses (Hofmann, Jacobs, \& Baratta, 1993; Vancouver, Millsap, \& Peters, 1994). HLM (Byrk, Raudenbush, \& Congdon, 1994), a software package designed to test hierarchical linear models, was used to test Hypotheses 11, 12, and 13. Unlike ordinary least squares (OLS) methods in which individual and group level residuals are not separately evaluated, this approach models both individual and group level residuals, thus acknowledging the partial interdependence of individuals within a group (Hofmann, 1997). Lower level within unit variance and higher level between unit variance in the dependent variable are assessed simultaneously. Using this technique, a Level 1, within group analysis is conducted first; the regression parameter estimates (slope, intercept) from this analysis are used as dependent variables in the Level 2, between group analysis.

The fact that the Level 1 parameter estimates are used as dependent variables in the Level 2 analysis raises the issue of the choice of centering method (Hofmann, 1997). In traditional regression analyses, the intercept variable is interpreted as the expected 
value of the dependent variable when the independent variable is zero. Because a zero value for procedural justice or job satisfaction is uninterpretable, these Level 1 predictors were rescaled to make them more meaningful. Two primary centering options exist (Hofmann, 1997). First, grand mean centering involves subtracting the grand mean from each employee's score on the predictor (i.e., procedural justice or job satisfaction). The intercept is the expected level of the outcome for a person with an "average" level of the predictor (e.g., an average level of procedural justice). Second, group mean centering involves subtracting the group mean from each employee's score on the predictor. The intercept is the expected outcome for a person with his/her group's average level of the predictor.

The choice of centering methods should be based on theoretical considerations (Hofmann \& Gavin, in press). In testing for interactions (i.e., moderational paradigms), only group mean centering allows the cross-level interaction to be separated out from the between-group interaction. However, when incremental paradigms are tested, as in the current study, the focus is whether the group level variable (i.e., procedural justice climate) contributes incrementally to the prediction of an individual level outcome (e.g., OCB) beyond individual level predictors (e.g., individual procedural justice). In this case, grand mean centering is most appropriate because it controls for group variance in the individual level variables while group mean centering does not. Thus, in the current study, grand mean centering was used to center the Level I predictors (individual procedural justice; job satisfaction). In general, large sample sizes are thought to be required for HLM analyses in order to have adequate power (i.e., .90) (Bassiri, 1988). 
However, given that there are no clear guidelines for determining exactly how large the sample sizes should be, the OLS requirement of ten observations per predictor was used. Thus, the three cross-level predictors in the present study required a minimum sample of 30 work groups with three to ten individuals comprising each work group. However, there may be a tradeoff among between and within work group observations (Hofmann, 1997). For instance, a large number of groups may compensate for a small number of observations per group and vice versa. Further, the statistical power for detecting Level 2 effects can be increased more by increasing the number of groups than by increasing the number of individuals per group (Bassiri, 1988). In contrast, the statistical power for detecting Level 1 effects hinges more on the total number of observations (Bassiri, 1988). Because the hypotheses in this dissertation concern Level 2 effects, it was more important to have a large number of work groups than to have a large number of individuals in each group.

To test hypotheses 11,12 , and 13, a three-step HLM procedure recommended by Hofmann (1997) was used. First, it had to be determined whether there was systematic between group variance in the dependent variables (turnover intentions, organizational commitment, and OCBs). A one-way ANOVA was used to partition the variance into within and between components. Specifically, a null model with no independent variables at Level 1 or 2 estimated the following equations:

Level 1: $\mathrm{DV}_{\mathrm{ij}}=\beta_{0 \mathrm{j}}+r_{\mathrm{ij}}$

Level 2: $\beta_{0 j}=\gamma_{00}+U_{o j}$

DV = turnover intentions, organizational commitment, or OCBs 
$\beta_{0 j}=$ mean turnover intentions, organizational commitment, or OCBs

$\gamma_{00}=$ grand mean on turnover intentions, organizational commitment, or

OCBs

Variance $\left(r_{i j}\right)=$ within group variance in turnover intentions,

organizational commitment, or OCBs

Variance $\left(\mathrm{U}_{\mathrm{oj}}\right)=$ between group variance in turnover intentions,

organizational commitment, or OCBs

Using these estimates, intraclass correlation coefficients (ICCs) representing the percentage of the total variance in the dependent variables that is between groups were computed using the following equation: ICC $=\tau_{00} / \tau_{00}+\sigma^{2}$ where $\tau_{00}$ is the between group variance in the dependent variable and $\sigma^{2}$ is the within group variance in the dependent variable. The ICC for turnover intentions was .10, indicating that $10 \%$ of the variance in turnover intentions is between groups. The ICC for organizational commitment was 13 , indicating that $13 \%$ of the variance in organizational commitment is between groups. The ICC for OCB was .21, indicating that $21 \%$ of the variance in OCB is between groups. A $\chi^{2}$ statistic was used to test the significance of these estimates. The results of these analyses are presented in Tables 9-11. Significant chi squares for turnover intentions $\left(\chi^{2}=54.10, \mathrm{p}<.01\right)$, organizational commitment $\left(\chi^{2}=\right.$ $60.11, \mathrm{p}<.01)$, and $\mathrm{OCB}\left(\chi^{2}=84.18, \mathrm{p}<.01\right)$ indicated that between group variance is significantly different from zero for each dependent variable. 
Table 9

HLM Analysis:

Null Model, Turnover Intentions

\section{Turnover Intentions}

Fixed effects

Coefficient

Standard error

Model for Level 1 intercept, $\beta_{0 j}$ Intercept, $\gamma_{00}$

.07

$\underline{\text { Random effects }}$

Standard deviation Variance component

Between group variance, $\tau_{00}$

.26

.07

Within group variance, $\sigma^{2}$

.81

.65

$\underline{\mathrm{n}}=34$ work groups, ${ }^{* *} \mathrm{p}<.01$ 
Table 10

HLM Analysis:

Null Model, Organizational Commitment

\section{Organizational Commitment}

Fixed effects

Coefficient

Standard error

Model for Level 1 intercept, $\beta_{0 j}$

Intercept, $\gamma_{\infty 0}$

$3.67^{* *}$

.06

Random effects

Standard deviation Variance component

Between group variance, $\tau_{00}$

.23

.05

Within group variance, $\sigma^{2}$

.64

.41

$\underline{\mathrm{n}}=34$ work groups, ${ }^{* *} \mathrm{p}<.01$ 
Table 11

HLM Analysis:

Null Model, OCB

Organizational Citizenship Behavior

Fixed effects

Coefficient

Standard error

Model for Level 1 intercept, $\beta_{0 j}$

Intercept, $\gamma_{\infty}$

$3.70^{* *}$

.08

Random effects

Standard deviation Variance component

Between group variance, $\tau_{00}$

Within group variance, $\sigma^{2}$

.70

.49

$\underline{\mathrm{n}}=34$ work groups, ${ }^{* *} \mathrm{p}<.01$ 
Second, it was determined whether there was significant variance in the intercept parameters estimated at Level 1 . Using a random coefficient regression model (Hofmann, 1997), the following equations were estimated:

Level 1: $D V_{i j}=\beta_{o j}+\beta_{i j}\left(\right.$ Procedural justice $\left.e_{i j}\right)+r_{i j}$

Level 2: $\beta_{o j}=\gamma_{00}+U_{o j}$

$$
\beta_{1 j}=\gamma_{10}+U_{1 j}
$$

DV = turnover intentions, organizational commitment, or OCBs

$\gamma_{\infty}=$ mean of the intercepts across groups

$\gamma_{10}=$ mean of the slopes across groups

Variance $\left(r_{i j}\right)=$ Level 1 residual variance

Variance $\left(\mathrm{U}_{\mathrm{oj}}\right)=$ Variance in the intercepts

Variance $\left(\mathrm{U}_{1 \mathrm{j}}\right)=$ Variance in the slopes

I-tests were used to test whether individual procedural justice was positively related to organizational commitment and organizational citizenship behaviors (Hypotheses 8 and 9) and whether job satisfaction was negatively related to turnover intentions (Hypothesis 14). The results of these analyses are reported in Tables 12-14. The results indicated that procedural justice was significantly associated with both organizational commitment $(\underline{t}=8.15, \underline{p}<.01)$ and $\mathrm{OCB}(\underline{t}=1.70, \underline{\mathrm{p}}<.05)$ and job satisfaction was significantly associated with tumover intentions $(\mathrm{t}=-7.48, \mathrm{p}<.01)$. Thus, Hypotheses 8,9 , and 14 were supported. Chi square tests were performed in order to determine if there was systematic variance in the intercepts across work groups for turnover intentions, organizational commitment, and organizational citizenship behaviors across groups. 
Table 12

HLM Analysis:

Random Coefficient Regression Model, Turnover Intentions

\begin{tabular}{lll}
\hline & \multicolumn{2}{c}{ Turnover Intentions } \\
Fixed effects & Coefficient & Standard error \\
\hline $\begin{array}{c}\text { Model for Level } 1 \text { intercept, } \beta_{0 j} \\
\text { Intercept, } \gamma_{00} \\
\begin{array}{c}\text { Model for Level } 1 \text { slope, } \beta_{1 j} \\
\text { Intercept, } \gamma_{01}\end{array}\end{array}$ & $2.53^{* *}$ & .06 \\
\hline
\end{tabular}

Random effects

Standard deviation Variance component

Between group variance in intercepts, $\tau_{00}$

.14

.02

Between group variance in slopes, $\tau_{11}$

.23

.05

Level 1 residual variance, $\sigma^{2}$

.70

.49

$\underline{\mathrm{n}}=34$ work groups, ${ }^{* *} \mathrm{p}<.01$ 
Table 13

HLM Analysis: Random Coefficient Regression Model, Organizational Commitment

\begin{tabular}{lcc}
\hline Fixed effects & Organizational Commitment \\
\hline $\begin{array}{c}\text { Model for Level } 1 \text { intercept, } \beta_{0 j} \\
\text { Intercept, } \gamma_{00}\end{array}$ & Standard error \\
$\begin{array}{c}\text { Model for Level } 1 \text { slope, } \beta_{1 j} \\
\text { Intercept, } \gamma_{01}\end{array}$ & $3.67^{* *}$ & .05 \\
\hline
\end{tabular}

$\underline{\text { Random effects }}$

Standard deviation Variance component

Between group variance in intercepts, $\tau_{00}$ .16 .02

Between group variance in slopes, $\tau_{11}$

.13

.02

Level 1 residual variance, $\sigma^{2}$

.55

.30

$\underline{\mathrm{n}}=34$ work groups, ${ }^{* *} \mathrm{p}<.01$ 
Table 14

HLM Analysis:

Random Coefficient Regression Model, OCB

Organizational Citizenship Behaviors

Fixed effects

Coefficient

Standard error

Model for Level 1 intercept, $\beta_{0 j}$ Intercept, $\gamma_{00}$

Model for Level 1 slope, $\beta_{1 j}$ $.13^{* *}$ .08 Intercept, $\gamma_{01}$

Random effects Standard deviation Variance component

Between group variance in intercepts, $\tau_{00}$ .38 .14

Between group variance in slopes, $\tau_{11}$ .18 .03

Level 1 residual variance, $\sigma^{2}$ .68 .47

$\underline{\mathrm{n}}=34$ work groups, ${ }^{* *} \mathrm{p}<.01$ 
Systematic variance in the intercepts was found for turnover intentions $\left(\chi^{2}=51.43, \mathrm{R}<\right.$ $.01)$, organizational commitment $\left(\chi^{2}=41.95, \mathrm{p}<.06\right)$, and $\mathrm{OCB}\left(\chi^{2}=82.91, \mathrm{p}<.01\right)$.

Third, to test Hypotheses 11,12, and 13, it was determined if variance in the intercept parameter could be predicted by the Level 2 independent variable, procedural justice climate. Hypotheses 11,12, and 13 (respectively) predicted that procedural justice climate would be related to tumover intentions, organizational commitment and OCBs. These models were estimated using the following equations:

Level 1: DV $=\beta_{\mathrm{oj}}+\beta_{\mathrm{ij}}\left(\right.$ Procedural justice $\left._{i j}\right)+r_{i j}$

Level 2: $\beta_{o j}=\gamma_{00}+\gamma_{01}$ (Procedural justice climate) $+U_{o j}$

$$
\beta_{1 j}=\gamma_{10}+U_{1 j}
$$

DV = turnover intentions, organizational commitment, OCBs

$\gamma_{\infty 0}=$ Level 2 intercept

$\gamma_{01}=$ Level 2 slope

$\gamma_{10}=$ Mean slope

Variance $\left(r_{i j}\right)=$ Level 1 residual variance

Variance $\left(\mathrm{U}_{\mathrm{oj}}\right)=$ Residual intercept variance

Variance $\left(U_{1 j}\right)=$ Variance in the slopes

T-tests were performed to test Hypotheses 11,12 , and 13. Results of this analysis are reported in Tables 15-17. Procedural justice climate did not explain significant variance in turnover intentions beyond the effects of job satisfaction $(t=-.06, p>.95)$; Hypothesis 11 was not supported. Procedural justice climate did not explain significant variance in organizational commitment beyond the effects of individual procedural justice 
Table 15

HLM Analysis: Intercepts as Outcomes Model, Turnover Intentions

\begin{tabular}{lll}
\hline & \multicolumn{1}{c}{ Turnover Intentions } \\
Fixed effects & Coefficient & Standard error \\
\hline $\begin{array}{l}\text { Model for Level } 1 \text { intercept, } \beta_{0 j} \\
\text { Intercept, } \gamma_{00}\end{array}$ & $2.55^{* *}$ & .43 \\
$\quad$ Procedural justice climate, $\gamma_{01}$ & -0.01 & .12 \\
$\begin{array}{l}\text { Model for Level } 1 \text { slope, } \beta_{1 j} \\
\text { Intercept, } \gamma_{10}\end{array}$ & $-.64^{* *}$ & .09 \\
\hline \begin{tabular}{l} 
Random effects \\
\hline
\end{tabular} & Standard deviation & Variance component \\
\hline $\begin{array}{l}\text { Residual variance in intercepts, } \tau_{00} \\
\text { Between group variance in slopes, } \tau_{11}\end{array}$ & .15 & .02 \\
\hline residual variance, $\sigma^{2}$ & .23 & .05 \\
\hline
\end{tabular}

$\underline{\mathrm{n}}=34$ work groups, ${ }^{* *} \mathrm{p}<.01$ 
Table 16

HLM Analysis: Intercepts as Outcomes Model, Organizational Commitment

\begin{tabular}{|c|c|c|}
\hline \multirow[b]{2}{*}{ Fixed effects } & \multicolumn{2}{|c|}{ Organizational Commitment } \\
\hline & Coefficient & Standard error \\
\hline $\begin{array}{l}\text { Model for Level } 1 \text { intercept, } \beta_{0 j} \\
\text { Intercept, } \gamma_{00}\end{array}$ & $3.81^{* *}$ & .38 \\
\hline Procedural justice climate, $\gamma_{01}$ & -.03 & .10 \\
\hline $\begin{array}{l}\text { Model for Level } 1 \text { slope, } \beta_{1 j} \\
\text { Intercept, } \gamma_{10}\end{array}$ & $.50^{* *}$ & .06 \\
\hline Random effects & Standard deviation & Variance component \\
\hline Residual variance in intercepts, $\tau_{00}$ & .16 & .03 \\
\hline Between group variance in slopes, $\tau_{11}$ & .13 & .02 \\
\hline Level 1 residual variance, $\sigma^{2}$ & .55 & .30 \\
\hline
\end{tabular}

$\underline{\mathrm{n}}=34$ work groups, ${ }^{* *} \mathrm{p}<.01$ 
Table 17

HLM Analysis:

Intercepts as Outcomes Model, OCB

Organizational Citizenship Behaviors

Fixed effects

Coefficient

Standard error

Model for Level 1 intercept, $\beta_{0 j}$

Intercept, $\gamma_{00}$

$2.75^{* *}$

.53

Procedural justice climate, $\gamma_{01}$

$.26^{*}$

.14

Model for Level 1 slope, $\beta_{1 \mathbf{j}}$

$.12^{* *}$

.08

Intercept, $\gamma_{10}$

$\underline{\text { Random effects }}$

Standard deviation Variance component

Residual variance in intercepts, $\tau_{\infty}$

Between group variance in slopes, $\tau_{11}$

.18

.03

Level 1 residual variance, $\sigma^{2}$

.68

.46

$\underline{\mathrm{n}}=.34$ work groups, ${ }^{* *} \mathrm{p}<.01$ 
perceptions $(t=-.35, \mathrm{R}>.72)$; Hypothesis 12 was not supported. Support was found for Hypothesis 13. Procedural justice climate explained significant variance in OCB beyond the effects of individual procedural justice perceptions $(t=1.82, \mathfrak{p}<.05)$. A summary of the hypotheses and their outcomes is reported in Table 18. 
Table 18

Summary of Hypotheses and their Outcomes

Hypothesis 1: Subordinates' perceptions of the quality of the exchange relationship with their supervisors will be positively related to subordinates' perceptions of procedural justice. Supported.

Hypothesis 2: Subordinates' perceptions of organizational support will be positively related to subordinates' perceptions of procedural justice. Supported.

Hypothesis 3: Subordinates' perceptions of leader monitoring will be positively related to subordinates' perceptions of procedural justice. Supported.

Hypothesis 4: The greater the level of work group cohesion, the greater the agreement of procedural justice climate. Supported.

Hypothesis 5: The greater the demographic similarity of the work group, the greater the agreement of procedural justice climate. Not supported.

Hypothesis 6: The greater the aggregate level of work group members' perceptions of the visibility of supervisors in demonstrating procedural justice, the greater the agreement of procedural justice climate. Supported.

Hypothesis 7: The greater the aggregate level of work group members' perceptions of organizational support, the greater the agreement of procedural justice climate. Not supported.

Hypothesis 8: Employee perceptions of procedural justice will be positively related to perceptions of organizational commitment. Supported.

Hypothesis 9: Employee perceptions of procedural justice will be positively related to supervisor ratings of organizational citizenship behaviors. Supported.

Hypothesis 10: Procedural justice climate will be negatively associated with work group absenteeism. Not supported.

Hypothesis 11: Procedural justice climate will be negatively associated with individuals' turnover intentions, beyond that explained by job satisfaction. Not supported.

Hypothesis 12: Procedural justice climate will be positively associated with organizational commitment, beyond that explained by individual procedural justice perceptions. Not supported.

Table continues 
Table 18, Continued

Hypothesis 13: Procedural justice climate will be positively associated with organizational citizenship behaviors, beyond that explained by individual procedural justice perceptions. Supported.

Hypothesis 14: Subordinates' perceptions of job satisfaction will be negatively related to their intentions to turnover. Supported. 


\section{Chapter 5: Discussion}

\section{Summary of Results}

The purpose of this dissertation was to present and test a model including contextual factors that contribute to the development of procedural justice climate; this climate was expected to affect work-related attitudes and behaviors beyond the effects of individual-level measures of procedural justice. In general, the results provided support for the model. The individual-level variables, leader-member exchange, perceived organizational support, and leader monitoring each contributed significantly to the development of individual procedural justice perceptions. Work group cohesion and the visibility of supervisors in demonstrating procedural justice each contributed significantly to the development of procedural justice climate agreement. The measures of work group heterogeneity and shared support perceptions, however, did not contribute significantly to the development of procedural justice climate agreement. With regard to the cross-level findings, procedural justice climate was positively associated with supervisors' ratings of subordinates' citizenship behaviors beyond the effects of individual-level procedural justice perceptions. Contextual effects were not detected for organizational commitment and turnover intentions. The individual-, group-, and crosslevel findings will be explained below.

\section{Individual Level Findings}

As noted in Chapter 2, identifying the independent factors that contribute to the formation of individual procedural justice perceptions remains a largely unexplored area in the existing justice literature. In this study I tested whether perceptions of leader- 
member exchange quality, organizational support, and leader monitoring contributed to the formation of individual procedural justice perceptions. First, subordinates' beliefs about their leader-member exchange quality were positively related to subordinates' procedural justice perceptions. This finding builds on previous research which suggested that the nature of interactions between leaders and subordinates mediates and structures subordinates' interpretations of organizational practices and events (Kozlowski \& Doherty, 1989). Specifically, subordinates who perceive they are members of "outgroup" supervisor relationships might perceive lower levels of procedural justice due to feelings of resentment (Yukl, 1989) or perceptions of being treated like a second-class citizen (Bass, 1990). On the other hand, subordinates who are perceive they are members of "in-group" supervisor relationships feel they receive support from their supervisors and maintain effective communication with their supervisors; these individuals are likely to hold enhanced perceptions of procedural justice.

Second, subordinates' perceptions of organizational support were positively associated with their perceptions of procedural justice. This indicates that employees' relationships with their organizations, not just their supervisors, contribute to their beliefs about procedural justice. The link between employee-organization relationships and employee's procedural justice levels has been explored in the psychological contract literature (Rousseau \& McLean Parks, 1992). Psychological contracts have been viewed as mutual expectations characterizing the obligations characterizing employeeorganization exchange relationships. When subordinates believe their psychological contracts have been breached (e.g., when the organization has not supported them), they 
are likely to adjust their procedural justice perceptions accordingly by considering the treatment they have received (Morrison \& Robinson, 1997). In contrast, employees who believe their employer is highly supportive are thought to trust the long-term faimess of organizations (Organ \& Konovsky, 1989).

Third, subordinates' judgments about the degree to which their supervisors obtain information about their individual performance (i.e., leader monitoring) was positively related to their procedural justice perceptions. As noted in Chapter 2, supervisors obtaining information about subordinates' performance (e.g., through observing their work) is thought to be an indicator of fair organizational procedures. Specifically, leader monitoring is a way of communicating to subordinates that supervisors base decisions on accurate, unbiased information that is applied consistently across employees. Thus, it follows that those employees who perceive a high degree of leader monitoring tend to have higher perceptions of procedural justice.

\section{Group Level Findings}

The group level hypotheses examined the factors that contribute to the development of procedural justice climate agreement (i.e., what causes employees within work groups to reach consensus on their collective perception of procedural justice).

Researchers have pointed to the importance of explicitly including agreement on a work environment variable as part of theoretical models involving contextual issues (Blies \& Halverson, 1997). Finding out what leads to consensus on a work environment variable is interesting in its own right, apart from examining the effects resulting from the absolute level of a climate variable. 
With regard to the group level hypothesis tests, work group cohesion and the visibility of supervisors in demonstrating procedural justice each contributed significantly to the development of procedural justice climate agreement. The measures of work group heterogeneity and shared support perceptions, however, did not contribute significantly to the development of procedural justice climate agreement. With regard to the work group cohesion finding, it is possible that work group members interpret procedural justice violations against a co-worker as violations against the whole work group. Consistent with the group values theory, all group members have an interest in the supervisor's treatment of any one employee. When a supervisor is seen treating a group member fairly, this sends a message to co-workers that their own best interests would be served in a future similar situation (Trevino, 1992). Such a situation seems most plausible in the case of cohesive groups since cohesive group members identify so strongly with their groups. Tyler (1989) has argued that when a supervisor treats a group member with high or low procedural justice, information about the employee's social status in the group is relayed not only to that member but also to other group members who identify with the employee. In groups where members are highly cohesive and members identify very strongly with the group, members might even put the group's interests above their own. In a lab study involving artificially created work groups, Markovsky (1985) found that when steps were taken to increase group identification, complaints for collective injustices became stronger than those for personal injustices. Previous justice research has focused on decisions about grievances and other processes, often ignoring the people who administer the justice each day (Niehoff \& 
Moorman, 1993). Given that supervisors are generally the chief "deliverers" of procedural justice in organizations, it is not surprising that work group perceptions of whether they have the opportunity to witness their supervisor publicly demonstrating procedural justice (e.g., through managing co-workers) was positively related to procedural justice climate agreement. This is consistent with the "mere exposure" explanation for how work group climates are thought to develop (Schneider \& Reichers, 1983). Because all work group employees work under the same supervisor, it makes sense that their perceptions of supervisor visibility would be related to procedural justice climate agreement.

The five demographic similarity measures did not, however, contribute to the development of procedural justice climate. The lack of a significant finding here may have resulted from limitations in the present sample. It may be that range restriction on each of the demographic characteristics hampered the detection of significant relationships. In this study, employees were highly homogeneous (i.e., white females) in terms of their demographics. Empirical tests of the model in different samples should help to give a more complete understanding of the relationship between demographic similarity and the formation of procedural justice climate.

Shared support perceptions also did not significantly contribute to the development of procedural justice climate. It is possible that shared support perceptions relate more to the absolute level of procedural justice climate itself, rather than to whether or not work group members agree on this level. A consideration of the conceptual meaning of the other two group level predictors, cohesion and supervisor 
visibility, should help to clarify this distinction. The work group cohesion and supervisor visibility constructs seem to require descriptive and neutral judgments rather than affective ones. To what extent members believe the group is a close one or perceive the supervisor is visible may be seen as being substantively different from whether or not members view a close knit work group positively or negatively, or view the idea of a visible supervisor positively or negatively. For example, a supervisor might be highly visible in publicly managing co-workers and group members may rate this supervisor accordingly as high on supervisor visibility; however, this measure of visibility says nothing about whether the supervisor is managing co-workers in a procedurally just or unjust way. In contrast, shared support perceptions are an affective evaluation of whether group members perceive support given to them by the organization as being good or bad. For example, if group members give a collectively high rating on the shared support scale, this indicates they perceive the organization as being very supportive. Thus, shared support perceptions would be more likely to be positively related to procedural justice climate itself than with procedural justice climate agreement. Hypothesis 10, which predicted that procedural justice climate would be significantly associated with lower levels of work group absenteeism, also did not find support in these data. The lack of a significant finding may have been due, in part, to the reduced sample size of eighteen work groups for the analysis. Future tests of the model in samples with a larger number of work groups should help to clarify the effect of procedural justice climate on work group absenteeism. 


\section{Cross Level Findings}

The findings for the cross level hypotheses were mixed. Hypothesis 13, which predicted that procedural justice climate would be positively associated with organizational citizenship behaviors beyond the effects of individual procedural justice perceptions, was supported. This finding builds on work providing evidence of a positive relationship of group-level factors such as group positive affect (George, 1990) and cohesion (Kidwell, Mossholder, \& Bennett, 1997) to OCB. Although the positive relationship between individual procedural justice perceptions and OCB has been well documented (e.g., Moorman, 1991; Niehoff \& Moorman, 1993), no research has examined a link between group-level procedural justice and OCB. Some researchers have acknowledged the possibility of this relationship. Lind and Earley (1991) maintained that procedural fairness activates group concerns because it elicits a sense of group harmony that causes group members to ignore their own interests without fear of being exploited by the group. Niehoff and Moorman (1993) further elaborated that, in the presence of fair group procedures, employees might use OCB as a way of supporting the group and improving its welfare.

The mechanism underlying the relationship between group-level procedural justice (i.e., procedural justice climate) and OCB may be explained by social information processing theory (SIP; Salancik \& Pfeffer, 1978). SIP indicates that employees' perceptions of their work environments are as much affected by social factors (e.g., cues from their co-workers) as by their own judgments. Realizing that relying solely on their own perceptions will not give them a complete view of their work environment, group 
members frequently turn to their co-workers to learn "how things are" (Hackman, 1992). Employees often think that co-workers have more knowledge of the work environment than they do. Other group members are, in turn, motivated to provide their co-workers with information concerning certain aspects of the work environment (Hackman, 1992). Those aspects that are most likely to be communicated include perceptions of the degree of fair treatment or how the pay and promotion systems work (Hackman, 1992). Topics that are less relevant to behavior and are not likely to disrupt the group (e.g., the number of employees in the organization; the color of the office walls) tend to be overlooked (Hackman, 1992).

Hackman (1992) argued that groups impact members' behavior through exposing members to "ambient stimuli," aspects of the work environment that members are exposed to as a regular part of their life in the group (e.g., interaction patterns among group members; evidence of fair or unfair treatment). Ambient stimuli vary considerably from work group to work group. These group-supplied stimuli are usually both immediate and highly salient and are the primary proximal cause of variation in work group members' individual behaviors. Considered the "glue" that keeps groups together, ambient stimuli provide a context for member behavior that significantly shapes what happens in the group (Hackman, 1992). In this way, procedural justice may create a context for member behavior. When group members have similar past experiences (e.g., groups that have had the opportunity to witness the supervisor managing co-workers), their behavior is most likely to be affected by ambient stimuli present in their work 
group. Ambient stimuli are thought to heighten the motivation of work group members to behave in a certain way (e.g., engage in OCBs).

Despite support for a contextual relationship between procedural justice climate and OCBs, the other two cross-level hypotheses were not supported in these data. Specifically, procedural justice climate was not negatively associated with employees' turnover intentions, beyond the effects of job satisfaction (Hypothesis 11). Procedural justice climate also was not positively associated with employees' reported levels of organizational commitment, beyond the effects of individual-level procedural justice perceptions (Hypothesis 12). The results of the first step of the HLM procedure (i.e., the null model at Level 1 or 2) provided some initial evidence of differences among the three dependent variables, turnover intentions, organizational commitment, and OCB. Although the chi square test indicated there was significant systematic between group variance in each dependent variable, the intraclass correlation coefficient was highest for OCB (.21), suggesting that $21 \%$ of the variance in employees' OCB is between groups, compared with $13 \%$ for organizational commitment and $10 \%$ for turnover intentions. This suggests that there many not have been sufficient variance in organizational commitment or turnover intentions to detect a contextual effect. Several possible theoretical explanations for the disparate cross-level findings are described below.

First, it has been suggested that work groups are more likely to influence employees' individual behaviors (e.g., OCB) than their attitudes (e.g., organizational commitment, turnover intentions) because work attitudes are more private and personal in nature than job behaviors. Hackman (1992) discussed two ways that ambient stimuli 
influence group members: informational influence and normative influence.

Informational influence occurs when ambient stimuli cause group members to revise their private attitudes. In contrast, normative influence occurs when ambient stimuli cause group members to change what they say their attitudes are--but not necessarily what they privately believe. If only normative influence has taken place and group members are merely acting as if they have certain attitudes because of normative expectations, then their behavior will be consistent with those attitudes only when the group is salient. This might help to explain why in the present study, procedural justice climate contributed to employees' level of OCBs, but not their organizational commitment or turnover intentions, which are more privately held attitudes.

Other support for the idea that group beliefs are less likely to affect individuals' attitudes, as opposed to their behaviors, may be found in the psychological contracts literature (Rousseau \& McLean Parks, 1992). The relationship between procedural justice and attitudes toward the organization such as organizational commitment and tumover intentions may be best understood as a psychological contract. Psychological or "relational" contracts are characterized by flexible, long-term social exchanges of loyalty and support between employees and their organizations (Rousseau \& McLean Parks, 1992). Perceptions of fair treatment by the organization are crucial to the continuation of the psychological contracts. Each employee has a unique psychological contract with the organization and, thus, each contract is idiosyncratically perceived and understood by the employee (Rousseau \& McLean Parks, 1992). Because psychological contracts are generally viewed as being highly subjective, group members are likely to 
disagree about the terms of their personal contract and the meaning of the terms (Rousseau \& McLean Parks, 1992). Accordingly, employees may feel that their organizational commitment as a reaction to treatment by the organization is something that is between the organization and themselves and has little to do with their work group's perceptions. This explanation is also congruent with a consideration of the conceptual referent embedded in each of the measures. Procedural justice climate is a group level measure with a group reference. Helping behavior also lends itself to a group context in that it pertains to a social phenomenon involving more than 1 person. It makes sense that employee perceptions of their group would be more related to their sense of community in the environment than with their personal relationships with the organization.

The disparate contextual findings of the present study relationships may also be explained by considering the immediacy of procedural justice's effects. Although individual procedural justice has consistently been linked with organizational commitment and turnover intentions in the literature, it may be that group-level procedural justice (i.e., procedural justice climate) evokes more immediate reactions from employees. Indeed, procedural justice has been regarded as having a "long term focus"; however, where the work group is concerned, the focus may be more immediate (e.g., with the demonstration of OCBs). It is possible that organizational commitment and turnover intentions as work reactions to procedural justice climate take longer to develop. When new employees enter an organization, their levels of organizational commitment and turnover intentions are likely to depend on their initial personal 
relationships with the organization and not on their collective work group perceptions. It is conceivable that it takes time for a work group to influence someone's work reactions beyond the work group itself and how things operate within the group. It may take longer for collective work group perceptions to change group members' perceptions of their loyalty to the organization. House et al. (1995) asserted that as the duration of employees' group relationships increases, they obtain more organizationspecific knowledge and begin to realize social significance attached to their roles in their work groups. Further, as employees become assimilated into their work groups, social cues (i.e., beliefs that co-workers have about the environment) will change their beliefs concerning their relationship to the organization and their psychological contract in it (House et al., 1995). When the work group perceives the organization's procedural justice negatively, employees are likely to reinterpret their relationship with the organization (e.g., through organizational commitment or tumover intentions). Hackman (1992) argued that "changes in beliefs and attitudes generally do not occur quickly; if a member has not accepted the group as a point of reference, its impact on his or her beliefs and attitudes may be nil" (p. 251). In sum, procedural justice climate's effects on OCB might be more immediate while it may take longer for procedural justice climate to affect employee attitudes toward the organization.

Thus, the findings presented here do not preclude the possibility of contextual relationships for organizational commitment and turnover intentions. Over time, procedural justice climate may translate into organizational commitment and turnover intentions. Future research using longitudinal designs should help to give a more 
complete understanding of the relationship of procedural justice climate with organizational commitment and turnover intentions.

Implications of the Proposed Model

Implications for theory and research

The work group interviews, along with the procedural climate questionnaire, provided evidence of isomorphism (House et al., 1995). Isomorphism suggests that the constituent components of a phenomenon (i.e., procedural justice), and the relationships among the components would be similar across levels of analysis (i.e., individual and group; House et al., 1995). The procedural justice construct is especially suited to the isomorphism explanation given that the sense making of environment attributes is one psychological process thought to be similar across several levels of analysis (House et al., 1995).

The model advances the procedural justice construct further into Reichers and Schneider's (1990) augmentation stage of conceptual development by exploring grouplevel factors. Most current conceptualizations of procedural justice have focused solely on the individual. This disregard for social context is reflective of traditional theories of organizational behavior:

Organizational theories, historically, have been founded on the basic assumption of the primacy of individual self-interest and have underemphasized the importance of the community as an important source of identity, and hence motivation, for the individual (Tsui, 1994, p. 265).

Yet, in order to fully understand organizational behavior and avoid misspecified models, it is important to examine the context in which the behavior occurs (House et al., 1995; 
Pfeffer \& Salancik, 1978). Indeed, researchers have recently sought to reaffirm context as the 'distinctive competence' of organizational behavior (i.e., through the linking of several levels of analysis) (Cappelli \& Sherer, 1991; House et al., 1995). Further, Jackson et al. (1991) argued for the need to examine the cross-level influence loop from the group context back to individual behavior, this loop has been ignored in the organizational behavior literature. The proposed model addresses the contributions of individual- and group-level factors simultaneously. The model suggests that procedural justice climate is an important contextual variable expected to influence work-attitudes and behaviors beyond the contributions of individual procedural justice perceptions.

The fact that agreement within groups was detected on the procedural justice climate measure provided evidence for the existence of procedural justice climate. This finding is most consistent with the group values explanation for procedural justice. Lind and Tyler (1988) argued that procedures are widely believed to be key elements of any enduring group and, therefore, procedural justice perceptions are key cognitions about groups. Since procedures are seen as manifestations of group values, they have symbolic significance for other cognitions about groups (Lind \& Tyler, 1988). Further, authority figures express their values through the procedures they use to make decisions and the perception that an authority is using unfair procedures may be evaluated with greater concern than the perception that an outcome is unfair (Tyler \& Lind, 1992).

The proposed model also contributes to theory by providing a link between the organizational justice and work group climate literatures. It has been suggested that in order to further theory development and escape the field's overfragmentation, 
organizational researchers should "fill in the gaps" through the linking of independent literatures (Pfeffer, 1993; Porter, 1996). Future research should identify other work group climates in organizations. For example, climates for distributive justice may emerge in organizations with "pay for performance" reward systems. In such organizations, work groups might differ in their shared beliefs about whether certain inputs (e.g., effort; skills) or outcomes (e.g., pay; benefits) are beneficial or detrimental. The model offers some implications for research design. Future investigations of procedural justice climate require organizations with formally defined work groups of interdependent individuals at the same level of the organizational hierarchy who perform similar tasks and share a supervisor. Such designs meet the criteria of conducting crosslevel analyses in that within group agreement is established. Another implication for research involves the type of methodologies employed. Because research on procedural justice climate is in the early stages of theory development, quantitative research methods should be complemented with qualitative methods. For instance, open-ended questions in semi-structured interviews of work groups (e.g., Schneider et al., 1992) should be used to examine (1) the various levels of analysis employees used to develop procedural justice perceptions, (2) the meaning employees attach to organizational events, (3) the role of the supervisor in the development of procedural justice perceptions and (4) the factors that contribute to an individual's perception of what makes a procedure fair. A final implication for research design involves the sample size. In general, large sample sizes are required for group-level and cross-level analyses in order to have enough power to detect significant effects. As noted earlier, the lack of a 
significant effect on absenteeism produced by procedural justice climate may have been due, in part, to the reduced sample size of eighteen work groups for the analysis.

\section{Future research areas}

In light of the finding that procedural justice climate affected employees' behaviors (OCB) beyond their individual perceptions, future research should examine the situational contingencies that determine when group members are most likely to be influenced by the group's perceptions. Hackman (1992) described several potential moderators of group influence. First, group influence over individual perceptions and behaviors is most likely to occur when aspects of the work environment are unclear or ambiguous. This might make procedural justice climate's effects even more salient to newcomers to the work group. Further, perhaps certain newcomers are more likely to be influenced by the work group's perceptions than others. It has been suggested that when group member's values are congruent with those of their work groups, group members' behaviors are more susceptible to group influence (House et al., 1995). Second, group influence is most likely to occur when the group is perceived by the employee as a credible (competent, successful, trustworthy, unanimous views) source. For example, if unanimity is considered an indicator of group credibility, future research could study whether the degree of agreement within a group on procedural justice climate affects the magnitude of the relationship between procedural justice climate and OCB. This test was not possible in the current study because there was little variance in within group agreement (i.e., group members largely agreed within all groups). Future research on groups with more variance in agreement would allow for a test of this 
notion. Finally, Hackman (1992) suggested that group members who feel poorly qualified to personally assess their work environment will be more influenced by group level perceptions. Future research could examine the effect of self-esteem on the relationship of procedural justice climate to outcomes. Perhaps procedural justice climate explains more variance in an employee's outcomes above and beyond individual perceptions when the individual scores low on a self-esteem measure.

Future research should examine whether procedural justice climate changes over time. According to collective sense making theory (House et al., 1995), group level perceptions are resistant to change. However, as individuals leave work groups over time, the group's composition is changed; thus, the procedural justice climate may change. Further, under decline conditions, macro variables such as climate are thought to become stronger determinants of micro behavior because long tenured employees, who are most intensely socialized, will remain \& short-term employees will be the first to involuntarily leave (House et al., 1995). Future research using longitudinal designs should help to clarify the dynamic nature of procedural justice climate.

Another area for future research is to examine procedural justice climate's effects on more traditional measures of performance or in-role behaviors. Some researchers have suggested that employees working in environments characterized by high levels of distrust (e.g., a negative procedural justice climate) would be expected to react through altering norms regarding their performance (Goodman et al., 1987). However, there has been little support for a procedural justice - performance relationship in previous research. The lack of findings may stem from situational constraints. Whereas measures 
of job attitudes like procedural justice are designed to maximize the amount of variance capable of being explained, measures of performance are often constrained by situational variables (Organ, 1977). For instance, technology may cause the amount of work to be done per unit time and per person to vary only within a small range (Organ, 1977). Further, a social exchange explanation for the justice - performance relationship assumes that individuals perceive increased performance as an appropriate form of reciprocation. It may be that, at least for some jobs, individuals are aware that significant increases in performance, beyond a minimally acceptable level, is not of much interest to organizational administrators. The more salient way to reciprocate may be through decreased absenteeism or lateness or increased citizenship behaviors. Future research should tailor the procedural justice climate outcome measures to the type of performance that is most salient to the particular research context.

Given that the current study used data from bank employees, the most salient performance outcomes might be customer satisfaction and behavior. The simultaneous delivery and receipt of services characterizing face-to-face employee-customer interactions in the service sector brings employees and customers close, blurring the boundary between employee and customer (Schneider \& Bowen, 1985). The idea of service organizations having highly permeable boundaries makes it likely that organizational practices extend beyond employees to affect customers as well. Previous research has found that employee perceptions of employer human resources practices were positively related to customer perceptions of service and negatively related to customer turnover intentions (Schneider \& Bowen, 1985). Future research could 
examine whether procedural justice climate also influences customer attitudes and behaviors. It may be that procedural justice climate affects service organization employees' level of citizenship behaviors toward customers, rather than simply toward the work group and organization. Clearly, service organizations concerned with managing customer perceptions about service will benefit from examining the role that the context in which the service is delivered plays in shaping the perceptions.

Given the relationship between procedural justice climate and OCB found in these data, it is plausible that procedural justice climate also affects behaviors at the other end of the prosocial - antisocial behavior spectrum. Some researchers have begun to examine some antisocial effects of individual procedural justice. For example, Greenberg (1990a; 1993) found that low perceptions of procedural justice predicted employee theft rates. Such findings have been explained in terms of "reciprocal deviance" (Kemper, 1966). When individuals perceive that authorities default on their obligations, anger and resentment cause employees to try to "even the score." When the individual is less powerful than the source of the injustice (e.g., the supervisor or the organization), efforts at "striking back" are usually indirect. Before resorting to more direct forms of retaliation, employees may engage in more subtle behaviors called organizational retaliatory behaviors (ORB; Skarlicki \& Folger, 1997). ORB has been considered analogous to OCB. In the same way that OCBs involve the small gestures that can be critical to organizational effectiveness, ORBs may not seem to be as detrimental as violent acts but, in the long run, may decrease organizational effectiveness. ORB includes behaviors such as giving a co-worker a "silent treatment" or 
intentionally working slowly. Skarlicki and Folger (1997) found that individual procedural justice perceptions were negatively associated with peer ratings of employees' demonstration of ORBs. Future research should expand this research to examine procedural justice climate's effect on ORB. Although no research has examined the effect of group level perceptions of procedural justice on ORB, some research has described the mechanism by which this effect might take place. Brockner and Wisenfeld (1996) theorized that when group members as a whole feel they are not treated fairly, each group member's self-esteem is diminished because unfair procedures symbolize to employees that the supervisor or organization has little respect for their dignity. In addition, Greenberg and Scott (1996) described research that identified group norms that affect employees' deviant behaviors (e.g., sharing tips on how to steal; quickly indoctrinating new group members into the highly cooperative nature of theft rituals).

Given the relationship of procedural justice climate to OCB found in these data, it is possible that procedural justice climate relates to other group-oriented variables as well. Most of the OCB items in this study were worded to reflect helping co-workers in the work group. It is possible that the climate measure is also related to other perceptions about the group such as intent to leave the work group. Future research should measure not only employees' tenure in the organization but also tenure in the work group. Previous research has found that similarity in date of entry into the work group is negatively related to employees' turnover (O'Reilly, Caldwell, \& Barnett, 1989). People who enter work groups together go through the same experiences, view the work environment from a common perspective, and have numerous opportunities to 
interact; this is thought to make them less likely to leave the work group (O'Reilly et al., 1989). Thus, work group tenure may moderate the relationship between procedural justice climate and outcomes such as turnover. Further, the detection of a group level antecedent to OCB in this study introduces another issue to be examined in future research: do group norms influence OCB? Given that there is some evidence to support group norms affecting ORB (Greenberg \& Scott, 1996), it is likely that group norms (e.g., reciprocity) would also influence behaviors that are more prosocial in nature.

Finally, future research should continue to explore "meso" level effects. House et al. (1995) reviewed published articles in Academy of Management Journal and Administrative Science Quarterly from 1988 to 1993 . Only a small number of studies looked at the effect of context on individual level variables (12 studies out of 412). Given current concern about team effectiveness in organizations, it is surprising that more research has not examined the unique effects of teams on individual behaviors and attitudes.

\section{Implications for practice}

The proposed model also has implications for practice. Supervisors should be concerned with managing work group perceptions of procedural justice, not just individual perceptions of procedural justice. In groups where there are strong shared beliefs about how the system works, assurances from supervisors are not likely to change the beliefs of group member (Hackman, 1992). Instead, fair procedural justice climates may be regarded as substitutes for management control (Schneider, 1990). Those organizational practices that get rewarded, supported, and expected are a way for top 
managers' objectives to be reinforced. Given the key role of shaping employee perceptions afforded to the supervisor in the model, organizations would be advised to ensure that supervisors are acting as procedural fairness lenses to their subordinates. Further, current conceptualizations of LMX development indicate that the supervisor rather than the subordinate has more control over the quality of the relationship between the supervisor and subordinate (Liden, Sparrowe, \& Wayne, 1997). Comments from employees provide evidence of the supervisor's role in shaping employees' procedural justice perceptions:

I do not feel that everyone is treated fairly at this branch. It all depends on what mood the manager is in when you need something.

In our branch, a lot of favoritism is shown to one individual member and, in turn, that brings down the morale of the rest of the group.

I feel like managers don't listen unless they feel like it.

Establishing high quality supervisor-subordinate and organization-subordinate relationships and fair procedures should result in positive consequences for organizations. Potential benefits indicated by the model include demonstrations of OCBs and organizational commitment and lower levels of withdrawal behaviors.

Another implication of the proposed model for practice involves employees' acceptance of organizational decisions. Individuals do not automatically accept the decisions made by authorities. Rather, they must first perceive that the authority is legitimate. How employees come to perceive supervisors as legitimate should be of interest to organizational researchers. Studies in legal (McEwen \& Maiman, 1984; Tyler, 1984, 1990), political (Tyler \& Caine, 1981; Tyler, Rasinski, \& Spodick, 1985) 
and organizational (Alexander \& Ruderman, 1987; Folger \& Konovsky, 1989; Tyler \& Lind, 1992) arenas indicate that employee perceptions of procedural justice play a key role in shaping judgments of the legitimacy of authority figures in organizations.

To the extent that work groups play a role in shaping individual perceptions, work groups will also affect the way authorities are viewed and subsequent employee behavior. Tyler and Lind (1992) offered two explanations for procedural justice's role in shaping perceptions about the legitimacy of authority figures. First, unfair procedures (e.g., poorly resolved disputes) can jeopardize long-term relationships whereas fair procedures can preserve positive relations among group members. This dynamic nature of group member relationships and supervisor-subordinate relationships should be addressed in future research through longitudinal studies. Second, in circumstances where it is not evident which outcome (e.g., decision) is most favorable, the only guarantee of decision quality is the use of fair procedures. In this way, procedural justice acts as a "social heuristic" (Tyler \& Lind, 1992, p. 134) that helps people assess whether an action (e.g., complying with an authority's decision) is correct without weighing the costs and benefits of the action.

\section{Limitations}

Several caveats should be considered in the interpretation of the results of the current study. First, the employee and manager surveys were collected at a single point in time. The use of cross-sectional data diminishes the ability to make causal inferences. Second, the design used to test the hypotheses was nonexperimental and, thus, precluded causal conclusions. All research designs involve tradeoffs. In the present study, 
experimental control was sacrificed for external validity. Third, the results presented here may not be generalizable to other organizations. For instance, in these data procedural justice climate affected employees' citizenship behaviors. This finding could be unique to service sector organizations. It could be that whereas prosocial behaviors are especially critical to work group effectiveness in service organizations, the same effect might not be detected in other industries such as manufacturing. Despite these important caveats, because the tested model was based on theory, more confidence can be placed in the findings. Further, the fact that a contextual effect was detected for OCB, rated by supervisors, and not for organizational commitment and turnover intentions, which were provided by subordinates, indicates that common method variance was not a serious problem in these data. 


\section{References}

Abbey, A., \& Dickson, J. W. 1983. R\&D work climate and innovation in semiconductors. Academy of Management Journal, 26: 362-368.

Abelson, M. A. 1993. Turnover cultures. Personnel and Human Resource Management, 11: 339-376.

Adams, J. S. 1965. Inequity in social exchange. In L. Berkowitz (Ed.), Advances in experimental social psychology (Vol. 2, pp. 267-299). New York: Academic Press.

Alexander, S., \& Ruderman, M. 1987. The role of procedural and distributive justice in organizational behavior. Social Justice Research, 1: 177-198.

Angle, H. L., \& Perry, J. L. 1986. Dual commitment and labor-management relationship climates. Academy of Management Journal, 19: 31-50.

Asch, S. E. 1956. Studies of independence and conformity: A minority of one against a unanimous majority. Psychological Monographs, 70, Whole \# 16.

Bass, B. M. 1990. Bass \& Stogdill's handbook of leadership. New York: Free Press.

Bassiri, D. 1988. Large and small sample properties of maximum likelihood estimates for the hierarchical linear model. Ph.D. thesis, Department of Counseling, Educational Psychology, and Special Education, Michigan State University.

Becker, T. E., Billings, R. S., Eveleth, D. M., \& Gilbert, N. L. 1996. Foci and bases of employee commitment: Implications for job performance. Academy of Management Journal, 39: 464-482.

Berger, J., Zelditch, M., Anderson, B., \& Cohen, B. P. 1972. Structural aspects of distributive justice: A status-value formulation. In J. Berger, M. Zelditch, \& B. Anderson (Eds.), Sociological theories in progress. 21-45. Boston: Houghton Mifflin.

Blau, P. 1964. Exchange and power in social life. New York: Wiley.

Blies, P. D., \& Halverson, R. R. in press. Group consensus and psychological wellbeing: A large field study. Journal of Applied Social Psychology. 
Brockner, J., \& Wisenfeld, B. M. 1996. An integrative framework for explaining reactions to decisions: Interactive effects of outcomes and procedures. Psychological Bulletin, 120: 189-208.

Brown, R. 1986. Social psychology. New York: The Free Press.

Byrk, A. S., \& Raudenbush, S. W. 1987. Application of hierarchical linear models to assessing change. Psychological Bulletin, 101: 147-158.

Byrk, A. S., \& Raudenbush, S. W., \& Congdon, R. J. 1994. Hierarchical linear models. Newbury Park, CA: Sage.

Cappelli, P., \& Sherer, P. D. 1991. The missing role of context in OB: The need for a meso-level approach. Research in Organizational Behavior, 13: 55-110.

Carsten, J. M., \& Spector, P. E. 1987. Unemployment, job satisfaction, and employee turnover: A meta-anaiytic test of the Muchinsky model. Journal of Applied Psychology, 72: 374-381.

Cartwright, D. \& Zander, A. 1968. Group dynamics: Research and theory (3rd ed.). New York: Harper \& Row.

Cohen, J., \& Cohen, P. 1983. Applied multiple regression / Correlation analysis for the behavioral sciences. Hillsdale, NJ: Lawrence Erlbaum Associates.

Conlon, D. E. 1993. Some tests of the self-interest and group-value models of procedural justice: Evidence from an organizational appeal procedure. Academy of Management Journal, 33: 833-846.

Cropanzano, R, \& Greenberg, J. 1997. Progress in organizational justice: Tunneling though the maze. Chapter to appear in C. L. Cooper \& I. T. Robertson (Eds.) International review of industrial and organizational psychology. New York: John Wiley \& Sons.

Dansereau, F., Jr., \& Alutto, J. A. 1990. Level-of-analysis issues in climate and culture research. In B. Schneider (Ed.) Organizational climate and culture. San Francisco: Jossey-Bass.

Dansereau, F., Graen, G., \& Haga, W. J. 1975. A vertical dyad approach to leadership within formal organizations. Organizational Behavior and Human Performance, 13: 46-78. 
Dirks, K. T., Cummings, L. L., \& Pierce, J. L. 1996. Psychological ownership in organizations: Conditions under which individuals promote and resist change. Research in Organizational Change and Development, 9: 1-23.

Dobbins, G. H., \& Zaccaro, S. J. 1986. The effects of group cohesion and leader behavior on subordinate satisfaction. Group \& Organization Studies, 11: 203219.

Eisenberger, R., Fasolo, P., \& Davis-LaMastro, V. 1990. Perceived organizational support and employee diligence, commitment, and innovation. Joumal of Applied Psychology, 75: 51-59.

Eisenberger, R., Huntington, R., Hutchison, S., \& Sowa, D. 1986. Perceived organizational support. Journal of Applied Psychology, 71: 500-507.

Fleishman, E. A. 1953. Leadership climate, human relations training, and supervisory behavior. Personnel Psychology, 6: 205-222.

Folger, R. \& Konovsky, M. A. 1989. Effects of procedural and distributive justice on reactions to pay raise decisions. Academy of Management Joumal, 32: 115-130.

Folger, R., Konovsky, M. A., \& Cropanzano, R. 1992. A due process metaphor for performance appraisal. Research in Organizational Behavior, 14: 129-177.

Fryxell, G. E., \& Gordon, M. E. 1989. Workplace justice and job satisfaction as predictors of satisfaction with union and management. Academy of Management Joumal, 32: 851-866.

Gerbing, D. W., \& Anderson, J. C. 1993. Monte Carlo evaluations of goodness-of-fit indices for structural equation models. In K. A. Bollen and J. S. Long (Eds.), Testing structural equation models. Newbury Park, CA: Sage.

George, J. M. 1990. Personality, affect, and behavior in groups. Joumal of Applied Psychology, 75: 107-116.

Goodman, P. S., Ravlin, E. C., \& Schminke, M. 1987. Understanding groups in organizations. Research in Organizational Behavior, 9: 121-173.

Graen, G. B., \& Scandura, T. A. 1987. Toward a psychology of dyadic organizing. Research in Organizational Behavior, 9: 175-208.

Green, S. G., Anderson, S. E., \& Shivers, S. L. 1996. Demographic and organizational influences on leader-member exchange and related work attitudes. Organizational Behavior and Human Decision Processes, 66: 203-214. 
Greenberg, J. 1986. Determinants of perceived fairness of performance evaluations. Journal of Applied Psychology, 71: 334-342.

Greenberg, J. 1990a. Employee theft as a reaction to underpayment inequity: The hidden cost of pay cuts. Journal of Applied Psychology, 75: 561-568.

Greenberg, J. 1990b. Organizational justice: Yesterday, today, and tomorrow. Џournal of Management, 16: 399-432.

Greenberg, J. 1993. Stealing in the name of justice: Informational and interpersonal moderators of theft reactions to underpayment inequity. Organizational Behavior and Human Decision Processes, 54: 81-103.

Greenberg, J., \& Folger, R. 1983. Procedural justice, participation, and the fair process effect in groups and organizations. In P. B. Paulus (Ed.), Basic group processes (pp. 235-256). New York: Springer-Verlag.

Greenberg, J., \& Scott, K. S. 1996. Why do workers bite the hands that feed them? Employee theft as a social exchange process. Research in Organizational Behavior, 18: 11-156.

Hackman. J. R. 1992. Group influences on individuals in organizations. Handbook of Industrial \& Organizational Psychology, 3: 199-267.

Hackman, J. R., \& Oldham, G. R. 1975. Development of the Job Diagnostic Survey. Journal of Applied Psychology, 60: 159-170.

Harris, R. J. 1976. Handling negative inputs: On the plausible equity formulae. Journal of Experimental Social Psychology, 12: 194-209.

Hofmann, D. A. 1997. An overview of the logic and rationale of hierarchical linear models. Journal of Management, 23: 723-744.

Hofmann, D. A., \& Gavin, M. B. in press. Centering decisions in hierarchical linear models: Theoretical and methodological implications for research in organizations. Journal of Management.

Hofmann, D. A., Jacobs, R, \& Baratta, J. 1993. Dynamic criteria and the measurement of change. Joumal of Applied Psychology 78: 194-204.

House, R., Rousseau, D. M., \& Thomas-Hunt, M. 1995. The meso paradigm: A framework for the integration of micro and macro organizational behavior. Research in Organizational Behavior, 17: 71-114. 
Jackson, S. E., Brett, J. F., Sessa, V. I., Cooper, D. M., Julin, J. A., \& Peyronnin, K. 1991. Some differences make a difference: Individual dissimilarity and group heterogeneity as correlates of recruitment, promotions, and turnover. Joumal of Applied Psychology, 76: 675-689.

James, K., \& Cropanzano, R 1990. Focus of attention and locus of control as moderators of fraternal justice effects. Social Justice Research, 4: 169-185.

James, L. R., Demaree, R. G., \& Wolf, G. 1984. Estimating within group interrater reliability with and without response bias. Joumal of Applied Psychology, 69: 85-98.

James, L. R., Demaree, R. G., \& Wolf, G. 1993. $r_{\text {we: }}$ : An assessment of within group interrater agreement. Journal of Applied Psychology, 78: 306-309.

James, L. R., Joyce, W. F., \& Slocum, J. W., Jr. 1988. Comment: Organizations do not cognize. Academy of Management Review, 13: 129-132.

Janis, I., \& Mann, L. 1977. Decision making. New York: Free Press.

Joreskog, K. G., \& Sorbom, D. 1993. LISREL 8 user's reference guide. Chicago: Scientific Software International.

Kemper, T. D. 1966. Representative roles and the legitimization of deviance. Social Problems: 13, 288-298.

Kidwell, R. E., Mossholder, K. W., \& Bennett, N. 1997. Cohesiveness and organizational citizenship behavior: A multilevel analysis using work groups and individuals. Joumal of Management, 6, 775-793.

Kim, W. C., \& Mauborgne, R. A. 1993. Procedural justice, attitudes, and subsidiary top management compliance with multinationals' corporate strategic decisions. Academy of Management Journal, 36: 502-526.

Konovsky, M. A., Folger, R, \& Cropanzano, R. 1987. Relative effects of procedural and distributive justice on employee attitudes. Representative Research in Social Psychology, 17: 15-24.

Kozlowski, S. W., \& Doherty, M. L. 1989. Integration of climate and leadership: Examination of a neglected issue. Journal of Applied Psychology, 74: 546-553. 
Leventhal, G. S. 1976. Fairness in social relationships. In J. W. Thibaut, J. T. Spence, \& R. C. Carson (Eds.), Contemporary topics in social psychology. Morristown, NJ: General Learning Press.

Liden, R. C., Sparrowe, R. T., \& Wayne, S. J. (1997). Leader-member exchange theory: The past and potential for the future. Research in Personnel and Human Resource Management, 15: 47-120.

Lind, E. A., \& Earley, 1992. Procedural justice and culture. International Joumal of Psychology, 27: 227-242.

Lind, E. A., \& Tyler, T. 1988. The social psychology of procedural justice. New York: Plenum.

Litwin, G. H., \& Stringer, R. A., Jr. 1968. Motivation and organizational climate. Boston: Division of Research, Harvard Business School.

Lott, A. J., \& Lott, B. E. 1965. Group cohesiveness as interpersonal attraction: A review of relationships with antecedent and consequent variables. Psychological Bulletin, 64: 259-309.

Major, D. A., Kozlowski, S. W., Chao, G. T., \& Gardner, P. D. 1995. Journal of Applied Psychology, 80: 418-431.

Markham, S. E., \& McKee, G. H. 1995. Group absence behavior and standards: A multilevel analysis. Academy of Management Journal 38: 1174-1190.

Markovsky, B. 1985. Toward a multilevel distributive justice theory. American Sociological Review, 50: 822-839.

Mathieu, J. E., \& Kohler, S. S. 1990. A cross-level examination of group absence influences on individual absence. Journal of Applied Psychology, 75: 217-220.

McEwen, C. A., \& Maiman, R. J. 1984. Mediation in small claims court. Law and Society Review, 18: 11-49.

McFarlin, D. B., \& Sweeney, P. D. 1992. Distributive and procedural justice as predictors of satisfaction with personal and organizational outcomes. Academy of Management Journal, 35: 626-637.

McGregor, D. M. 1960. The human side of enterprise. New York: McGraw-Hill. 
Miceli, M. P., \& Near, J. P. 1985. Characteristics of organizational climate and perceived wrongdoing associated with whistle-blowing decisions. Personnel Psychology, 38: 525-544.

Miesing, P., \& Preble, J. F. 1985. Group processes and performance in a complex business simulation. Small Group Behavior, 16: 325-338.

Mobley, W. H. 1977. Intermediate linkages in the relationship between job satisfaction and employee turnover. Journal of Applied Psychology, 62: 237-240.

Moorman, R. R. 1991. Relationship between organizational justice and organizational citizenship behaviors: Do fairness perceptions influence employee citizenship? Journal of Applied Psychology, 76: 845-855.

Morrison, E. W., \& Robinson, S. L. 1997. When employees feel betrayed: A model of how psychological contract violation develops. Academy of Management Review, 22: 226-256.

Mossholder, K. W., Bennett, N., \& Martin, C. L. in press. A multilevel analysis of procedural justice context. Journal of Organizational Behavior.

Mowday, R. T., Steers, R. M., \& Porter, L. W. 1979. The measurement of organizational commitment. Journal of Vocational Behavior, 14: 224-247.

Nicholson, N., \& Johns, G. 1985. The absence culture and the psychological contract Who's in control of absence? Academy of Management Review, 10: 397-407.

Niehoff, B. P., \& Moorman, R. H. 1993. Justice as a mediator of the relationship between methods of monitoring and organizational citizenship behavior. Academy of Management Journal, 36: 527-556.

Nunnally, J. C. 1978. Psychometric theory. New York: McGraw-Hill.

O'Reilly, C. A., III, Caldwell, D. F., \& Barnett, W. P. 1989. Work group demography, social integration, and turnover. Administrative Science Quarterly, 34: 21-37.

Organ, D. W. 1977. A reappraisal and reinterpretation of the satisfaction - causes performance hypothesis. Academy of Management Review, 2: 46-53.

Organ, D. W. 1990 . The motivational basis of organizational citizenship behavior. Research in Organizational Behavior, 12: 43-72. 
Organ, D. W. , \& Hamner, W. C. 1982. Organizational behavior. Plano, TX: Business Publications.

Organ, D. W., \& Konovsky, M. 1989. Cognitive versus affective determinants of organizational citizenship behavior. Journal of Applied Psychology, 74: 157-164.

Oswald, S. L., Mossholder, K. W., \& Harris, S. G. 1994. Vision salience and strategic involvement: Implications for psychological attachment to organization and job. Strategic Management Journal, 15: 477-489.

Peter. J. P., \& Olson, J. C. 1993. Consumer Behavior and Marketing Strategy. Boston, MA: Irwin.

Podsakoff, P. M., \& Organ, D. W. 1986. Self-reports in organizational research: Problems and prospects. Journal of Management, 12: 531-544.

Pfeffer, J. 1983. Organizational demography. Research in Organizational Behavior, 5: 299-357.

Price, J. L., \& Mueller, C. W. (1986). Handbook of organizational measurement. Marshfield, MA: Pittman.

Pfeffer, J., \& Salancik, G. R. 1978. The external control of organizations: A resource dependence perspective. New York: Harper \& Row.

Porter, L. W. 1996. Forty years of organization studies: Reflections from a micro perspective. Administrative Science Quarterly, 41: 262-269.

Reichers, A. E., \& Schneider, B. 1990. Climate and culture: An evolution of constructs. In B. Schneider (Ed.), Organizational climate and culture (pp. 5-39). San Francisco, CA: Jossey-Bass.

Rentsch, J. R. 1990. Climate and culture: Interaction and qualitative differences in organizational meanings. Journal of Applied Psychology, 75: 668-681.

Renwick, P. A. 1975. Perception and management of superior-subordinate conflict. Organizational Behavior and Human Performance, 13: 444-456.

Rousseau, D. M. 1985. Issues of level in organizational research: Multi-level and crosslevel perspectives. Research in Organizational Behavior, 7: 1-37. 
Rousseau, D. M., \& McLean Parks, J. 1992. The contracts of individuals and organizations. In L. L. Cummings \& B. M. Staw (Eds.), Research in Organizational Behavior, 15: 1-47.

Salancik, G. R, \& Pfeffer, J. 1978. A social information processing approach to job attitudes and task design. Administrative Science Quarterly, 23: 224-252.

Scandura, T. A., \& Graen, G. B. 1984. Moderating effects of initial leader-member exchange status on the effects of a leadership intervention. Journal of Applied Psychology, 69: 428-436.

Schneider, B. 1987. The people make the place. Personnel Psychology, 40: 437-453.

Schneider, B. 1990. The climate for service: An application of the climate construct. In B. Schneider (Ed.), Organizational climate and culture (pp. 383-412). San Francisco: Jossey-Bass.

Schneider, B., \& Bartlett, C. J. 1968. Individual differences and organizational climate I: The research plan and questionnaire development. Personnel Psychology, 21: 323-333.

Schneider, B., \& Bartlett, C. J. 1970. Individual differences and organizational climate II: Measurement of organizational climate by the multi-trait, multi-rater matrix. Personnel Psychology, 23: 493-512.

Schneider, B., \& Bowen, D. E. 1985. Employee and customer perceptions of service in banks: Replication and extension. Journal of Applied Psychology, 70: 423-433.

Schneider, B., Parkington, J. J., \& Buxton, V. M. 1980. Employee and customer perceptions of service in banks. Administrative Science Ouarterly, 25: 252-267.

Schneider, B., \& Reichers, A. 1983. On the etiology of climates. Personnel Psychology, 36: $19-40$.

Schneider, B., Wheeler, J. K., \& Cox, J. F. 1992. A passion for service: Using content analysis to explicate service climate themes. Journal of Applied Psychology, 77: 705716.

Settoon, R. P., Bennett, N., \& Liden, R. C. 1996. Social exchange in organizations: Perceived organizational support, leader-member exchange, and employee reciprocity. Journal of Applied Psychology, 81: 219-227.

Shaw, M. E. 1981. Group Dynamics, 3rd ed. New York: McGraw-Hill. 
Sheppard, B. H., \& Lewicki, R. J. 1987. Toward general principles of managerial faimess. Social Justice Research, 1: 161-176.

Sherif, M. 1936. The psychology of social norms. New York: Octagon.

Skarlicki, D. P., \& Folger, R. 1997. Retaliation in the workplace: The roles of distributive, procedural, and interactional justice. Journal of Applied Psychology: 82, 434-443.

Stepina, L. P., \& Perrewe, P. L. 1991. The stability of comparative referent choice and feelings of inequity: A longitudinal field study. Journal of Organizational Behavior, 12: 185-200.

Stogdill, R. M. 1972. Group productivity, drive, and cohesiveness. Organizational Behavior and Human Performance, 8: 26-53.

Tajfel, H. 1981. Human groups and social categories. Cambridge, England: Cambridge University Press.

Taylor, C. W. 1972. Climate for creativity. Elmsford, N. Y.: Pergamon.

Tett, R. P., \& Meyer, J. P. 1993. Job satisfaction, organizational commitment, turnover intention, and turnover: Path analyses based on meta-analytic findings. Personnel Psychology, 46: 259-293.

Thibaut, J., \& Walker, L. 1975. Procedural justice: A psychological analysis. Hillsdale, NJ: Lawrence Erlbaum Associates.

Thomas, J. B., Shankster, L. J., \& Mathieu, J. E. 1994. Antecedents to organizational issue interpretation: The roles of single level, cross level, and content cues. Academy of Management Journal, 37: 1252-1284.

Trevino, L. K. 1992. The social effects of punishment in organizations: A justice perspective. Academy of Management Review, 17: 647-676

Tsui, A. S. 1994. Reputational effectiveness: Toward a mutual responsiveness framework. Research in Organizational Behavior, 16: 257-307.

Tsui, A. S., Egan, T. D., \& O'Reilly, C. A., III. 1992. Being different: Relational demography and organizational attachment. Administrative Science Quarterly, 37: 549-579. 
Tsui, A.S., Pearce, J. L., Porter, L. W., \& Hite, J. P. 1995. Choice of employeeorganization relationship: Influence of external and internal organizational factors. Research in Personnel and Human Resources Management, 13: 117 151.

Tyler, T. R. 1984. The role of perceived injustice in defendant's evaluations of their courtroom experience. Law and Society Review, 18: 51-74.

Tyler, T. R. 1989. The psychology of procedural justice: A test of the group-value model. Journal of Personality and Social Psychology, 57: 830-838.

Tyler, T. R. 1990. Why people obey the law: Procedural justice, legitimacy, and compliance. New Haven, CT: Yale University Press.

Tyler, T. R., \& Caine, A. 1981. The role of distributional and procedural fairness in the endorsement of formal leaders. Journal of Personality and Social Psychology, 41: $642-655$.

Tyler, T. R., \& Lind, E. A. 1992. A relational model of authority in groups. In M. P. Zanna (Ed.), Advances in experimental social psychology, 25: 115-191. San Diego: Academic Press.

Tyler, T. R., Rasinski, K., \& Spodick, N. 1985. The influence of voice on satisfaction with leaders: Exploring the meaning of process control. Journal of Personality and Social Psychology, 48: 72-81.

Vancouver, J. B., Millsap, R. E., \& Peters, P. 1994. Multilevel analysis of organizational goal congruence. Journal of Applied Psychology, 79: 666-680.

Wayne, S. J., Shore, L. M., \& Liden, R. C. 1997. Perceived organizational support and leader-member exchange: A social exchange perspective. Academy of Management Journal, 40: 82-111.

Weick, K. E. 1992. Agenda settings in organizational behavior: A theory-focused approach. Journal of Management Inquiry, 1: 171-183.

West, S. G., Finch, J. F., \& Curran, P. J. 1995. Structural equation models with nonnormal variables: Problems and remedies. In R. H. Hoyle (Ed.), Structural equation modeling: Concepts, issues, and applications: 37-55. Thousand Oaks, CA: Sage. 
Williams, L. J., \& Anderson, S. E. 1991. Job satisfaction and organizational commitment as predictors of organizational citizenship and in-role behaviors. Journal of Management, 17: 601-617.

Williams, L. J., \& Hazer, J. T. 1986. Antecedents and consequences of satisfaction and commitment in turnover models: A reanalysis using latent variable structural equation methods. Journal of Applied Psychology 71: 219-231.

Yukl, G. 1989. Managerial leadership: A review of theory and research. Journal of Management, 15: 251-289.

Zohar, D. 1980. Safety climate in industrial organizations: Theoretical and applied implications. Journal of Applied Psychology, 65: 96-102. 


\section{Appendix A: Scale items}

Leader-member exchange (Scandura \& Graen, 1984)

1. I know where I stand...I usually know how satisfied my supervisor is with what I do.

2. My supervisor understands my job problems and needs.

3. My supervisor recognizes my potential.

4. Regardless of how much formal authority my supervisor has built into his/her position, he/she would use that power to help me solve problems in my work.

5. My supervisor would "bail me out" at his/her expense.

6. I have an effective working relationship with my supervisor.

7. I would defend and justify my supervisor's decisions if he/she were not present to do so.

\section{Perceived organizational support (Eisenberger, Huntington, Hutchison, \& Sowa, 1986)}

This organization ...

1. Strongly considers my goals and values.

2. Helps me if I have a problem.

3. Really cares about my feelings.

4. Is willing to extend itself in order to help me perform my job to the best of my ability.

5 . Would fail to notice my work, even if I did the best job possible. (R)

6. Cares about my general satisfaction at work.

7. Shows very little concern for me. $(R)$

8. Takes pride in my accomplishments at work.

Leader monitoring (Niehofr \& Moorman, 1993)

My supervisor frequently ...

1. Walks around the workplace.

2. Watches me as I work.

3. Just stands or sits and observes me working.

4. Carefully examines the work I have completed.

5. Checks to see if I am working efficiently.

Individual procedural justice (Greenberg, 1986)

In this organization ...

1. Consistent rules and procedures are used to make decisions about things that affect me.

2. Personal motives or biases influence decisions that affect me. (R)

3. Decisions that affect me are made ethically.

4. Accurate information is used to make decisions that affect me.

5. My input is obtained prior to making decisions.

6. I am given the opportunity to modify decisions that have already been made.

7. The reasons behind the decisions that affect me are explained. 
8. Concern is shown for my rights.

9. There is a real interest in trying to be fair to me.

Distributive justice (Price \& Mueller, 1986)

I am fairly rewarded ...

1. Considering the responsibilities I have.

2. Taking into account the amount of education and training that I have had.

3. In view of the amount of experience that I have.

4. For the amount of effort that I put forth.

5. For work that I have done well.

6. For the stresses and strains of my job.

Work group cohesion (Dobbins \& Zaccaro, 1986)

As a whole, the people in my work group feel that ...

1. If given the chance, we would choose to leave our work group and join another. (R)

2. We get along well together.

3. We will readily defend each other from criticism from outsiders.

4. We are really a part of our work group.

5. We look forward to being with our work group each day

6. We generally do not get along with each other. (R)

7. Many of us in the group are friends.

8. Our work group is a close one.

Visibility of supervisors in demonstrating procedural justice

As a whole, the people in my work group feel that around here . . .

1. We have the opportunity to observe our supervisor implementing organizational policies in our work group.

2. We see our supervisor as a key administrator of this organization's policies, practices, and procedures.

3. Many times we have witnessed our supervisor enforcing organizational rules for doing things.

4. We have seen our supervisor make decisions about our work group that are consistent with company policies.

Shared support perceptions (adapted from Eisenberger, Huntington, Hutchison, \& Sowa, 1986)

This organization ... .

1. Strongly considers my work group's goals and values.

2. Helps my work group if we have a problem.

3. Really cares about my work group's feelings.

4. Is willing to extend itself in order to help my group perform its job to the best of its ability.

5. Would fail to notice my group's work, even if we did the best job possible. (R) 
6. Cares about my work group's general satisfaction.

7. Shows very little concern for my work group. (R)

8. Takes pride in my work group's accomplishments.

Procedural justice climate (adapted from Greenberg, 1986)

As a whole, the people in my work group feel that around here ...

1. Consistent rules and procedures are used to make decisions about things that affect our group.

2. Personal motives or biases influence decisions that affect our group. (R)

3. Decisions that affect our group are made ethically.

4. Accurate information is used to make decisions.

5. Our input is obtained prior to making decisions.

6. We're given the opportunity to modify decisions that have already been made.

7. The reasons behind the decisions that affect our group are explained.

8. Concern is shown for our rights.

9. There is a real interest in trying to be fair to us as a group.

Organizational Commitment (Mowday, Steers, \& Porter, 1979)

1. I am willing to put in a great deal of effort beyond that normally expected in order to help this organization be successful.

2. I talk up this organization to my friends as a great organization to work for.

3. I would accept almost any type of job assignment in order to keep working for this organization.

4. I find that my values and the organization's values are very similar.

5. I am proud to tell others that I am part of this organization.

6. This organization really inspires the very best in me in the way of job performance.

7. I am extremely glad that I chose this organization to work for over others I was considering at the time I joined.

8. I really care about the fate of this organization.

9. For me this is the best of all possible organizations for which to work.

Turnover intentions (Mowday, Steers, \& Porter, 1979)

1. I feel very little loyalty to this organization.

2. I could just as well be working for a different organization as long as the type of work was similar.

3. It would take very little change in my present circumstances to cause me to leave this organization.

4. There's not too much to be gained by sticking with this organization indefinitely.

5. Often, I find it difficult to agree with this organization's policies on important matters relating to its employees.

6. Deciding to work for this organization was a definite mistake on my part. 
Organizational citizenship behaviors (Williams \& Anderson, 1991)

This employee ...

1. Helps others who have been absent.

2. Helps others who have heavy work loads.

3. Takes time to listen to co-workers' problems and worries.

4. Goes out of way to help new employees.

5. Takes a personal interest in other employees.

6. Passes along information to co-workers.

7. Assists me with my work when not asked.

Job satisfaction

1. All things considered, I am satisfied with my job.

2. I like my job.

3. I am generally satisfied with the work I do in this job. 


\section{Appendix B: Employee Survey}

\section{PART 1: YOUR ORGANIZATION}

The following questions concern your work-related attitudes. Please indicate the degree of your agreement or disagreement with each statement. In the blank next to each statement, write the number $1,2,3,4$, or 5 which corresponds to the following scale:

\section{Strongly Disagree 2. Disagree 3. Not Sure 4. Agree 5. Strongly Agree}

I am willing to put in a great deal of effort beyond that normally expected in order to help this organization be successful.

I talk up this organization to my friends as a great organization to work for.

I would accept almost any type of job assignment in order to keep working for this organization.

I find that my values and the organization's values are very similar.

I am proud to tell others that I am part of this organization.

This organization really inspires the very best in me in the way of job performance.

I am extremely glad that I chose this organization to work for over others I was considering at the time I joined.

I really care about the fate of this organization.

For me this is the best of all possible organizations for which to work.

I feel very little loyalty to this organization.

I could just as well be working for a different organization as long as the type of work was similar.

It would take very little change in my present circumstances to cause me to leave this organization.

There's not too much to be gained by sticking with this organization indefinitely. Often, I find it difficult to agree with this organization's policies on important matters relating to its employees.

Deciding to work for this organization was a definite mistake on my part.

All things considered, I am satisfied with my job.

I like my job.

I am generally satisfied with the work I do in this job.

This organization ...

Strongly considers my goals and values.

_ Helps me if I have a problem.

Really cares about my feelings.

Is willing to extend itself in order to help me perform my job to the best of my ability. 
Would fail to notice my work, even if I did the best job possible.

Cares about my general satisfaction at work.

Shows very little concern for me.

Takes pride in my accomplishments at work.

I am fairly rewarded ...

Considering the responsibilities I have.

- Taking into account the amount of education and training that I have had.

In view of the amount of experience that I have.

For the amount of effort that I put forth.

For work that I have done well.

For the stresses and strains of my job.

In this organization ...

Consistent rules and procedures are used to make decisions about things that affect me.

Personal motives or biases influence decisions that affect me.

— Decisions that affect me are made ethically.

Accurate information is used to make decisions that affect me.

My input is obtained prior to making decisions.

I am given the opportunity to modify decisions that have already been made.

- The reasons behind the decisions that affect me are explained.

- Concern is shown for my rights.

_ There is a real interest in trying to be fair to me.

\section{PART 2: YOUR WORK GROUP}

The following questions concern the employees in your branch (your work group).

When responding to these questions, keep your group as a whole in mind.

As a whole, the people in my work group feel that ...

If given the chance, we would choose to leave our work group and join another.

We get along well together.

We will readily defend each other from criticism from outsiders.

We are really a part of our work group.

We look forward to being with our work group each day.

We generally do not get along with each other.

Many of us in the group are friends.

- Our work group is a close one.

As a whole, the people in my work group ...

Believe that groups can take on most challenges.

Believe they are a capable work team. 
Believe work teams can cope with difficult goals with less stress than an individual employee.

Feel confident they can get things done.

- Believe they can do their work better by learning new ways to be efficient.

As a whole, the people in my work group feel that around here...

We have the opportunity to observe our supervisor implementing organizational policies in our work group.

We see our supervisor as a key administrator of this organization's policies, practices, and procedures.

Many times we have witnessed our supervisor enforcing organizational rules for doing things.

We have seen our supervisor make decisions about our work group that are consistent with company policies.

Consistent rules and procedures are used to make decisions about things that affect our group.

Personal motives or biases influence decisions that affect our group.

Decisions that affect our group are made ethically.

Accurate information is used to make decisions.

Our input is obtained prior to making decisions.

We're given the opportunity to modify decisions that have already been made.

The reasons behind the decisions that affect our group are explained.

Concern is shown for our rights.

There is a real interest in trying to be fair to us as a group.

As a whole, the people in my work group feel that this organization ...

Strongly considers my work group's goals and values.

Helps my work group if we have a problem.

Really cares about my work group's feelings.

Is willing to extend itself in order to help my group perform its job to the best of its ability.

Would fail to notice my group's work, even if we did the best job possible. (R)

Cares about my work group's general satisfaction.

Shows very little concern for my work group. (R)

Takes pride in my work group's accomplishments.

\section{PART 3: YOUR SUPERVISOR}

The following questions concern your working relationship with your immediate supervisor. This is the person who most directly supervises most of the work you do.

I know where I stand...I usually know how satisfied my supervisor is with what I do.

My supervisor understands my job problems and needs. 
My supervisor recognizes my potential.

Regardless of how much formal authority my supervisor has built into his/her position, he/she would use that power to help me solve problems in my work.

My supervisor would "bail me out" at his/her expense.

I have an effective working relationship with my supervisor.

- I would defend and justify my supervisor's decisions if he/she were not present to do so.

My supervisor frequently...

Walks around the workplace.

Watches me as I work.

Just stands or sits and observes me working.

Carefully examines the work I have completed.

Checks to see if I am working efficiently.

How long have you been employed at this organization?

Years Months

Circle your level of education:

l=Some high school $2=$ High school degree $3=$ Some college $4=$ College degree

$5=$ Some graduate school $6=$ Graduate degree

Circle your gender: $\quad 1=$ Male $\quad 2=$ Female

Circle your race: 1=White 2=African-American 3=Hispanic $4=$ Asian

$5=$ Other

What is your age? 


\section{Appendix C: Supervisor Survey}

Below are statements regarding behaviors that employees may or may not engage in at work. Please complete one of these one-page surveys for each employee you supervise.

Indicate the degree of your agreement or disagreement with each statement. In the blank next to each statement, write the number $1,2,3,4$, or 5 which corresponds to the following:

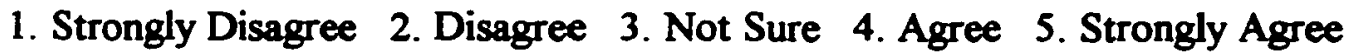

This employee . . .

Helps others who have been absent.

Helps others who have heavy work loads.

Takes time to listen to co-workers' problems and worries.

Goes out of his/her way to help new employees.

Takes a personal interest in other employees.

_ Passes along information to co-workers.

- Assists me with my work when not asked.

Please rate this employee on the following dimensions. In the blank next to each statement, write the number $1,2,3,4$, or 5 which corresponds to the following statements about your expectations about his/her work:

1. Falls significantly below expectations 2. Fails to meet expectations

3. Meets expectations 4. Exceeds expectations 5. Far exceeds expectations
Attendance
Conscientiousness
Dependability
Work ethic
Collegiality
Productivity
Accuracy of work
Overall performance 
Vits

Stefanie E. Naumann received her bachelor of science degree in Psychology from Tulane University. She is a co-author of a paper appearing in Academy of Management Journal. She has presented papers at annual meetings of the Academy of Management, Society for Industrial and Organizational Psychology, and Southern Management Association. Her research interests include organizational justice, climate, and citizenship behaviors. She will receive the degree of Doctor of Philosophy at Spring Commencement, 1998. 


\section{DOCTORAL EXAMINATION AND DISSERTATION REPORT}

Candidate: Stefanie Elizabeth Naumann

Major Field: Business Administration (Management)

Iitle of Dibaertation: A Case for Procedural Justice Climate:

Development and Test of a Multilevel Model

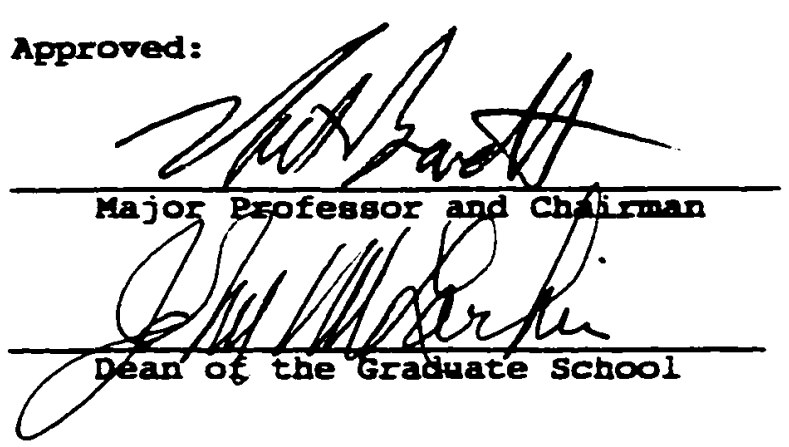

EXAMINING COMMITTEE:
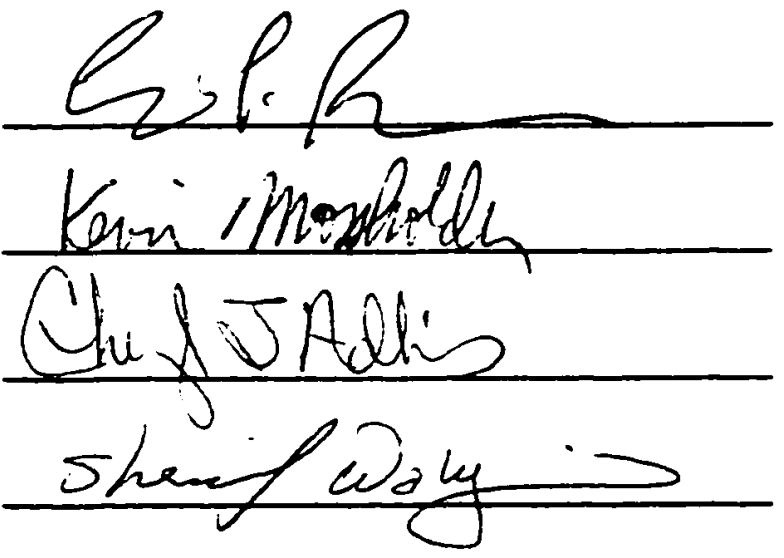

\section{Date of Examination:}

April 3, 1998 


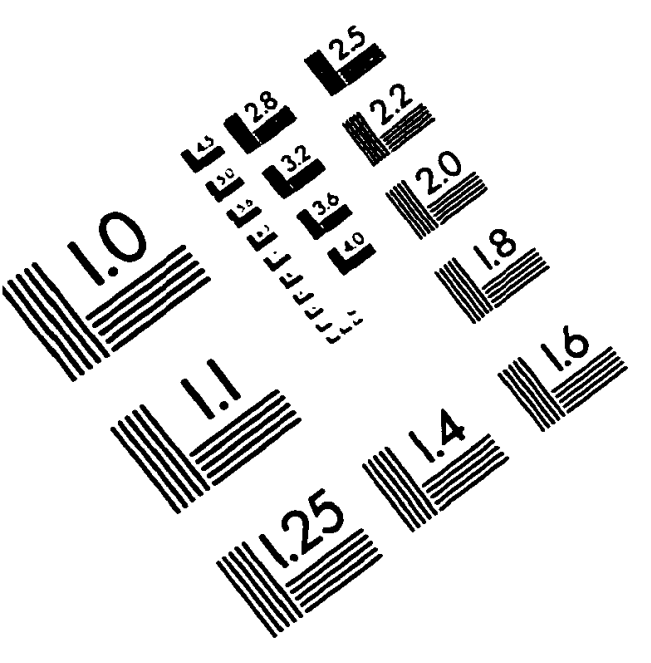

\section{IMAGE EVALUATION TEST TARGET (QA-3)}
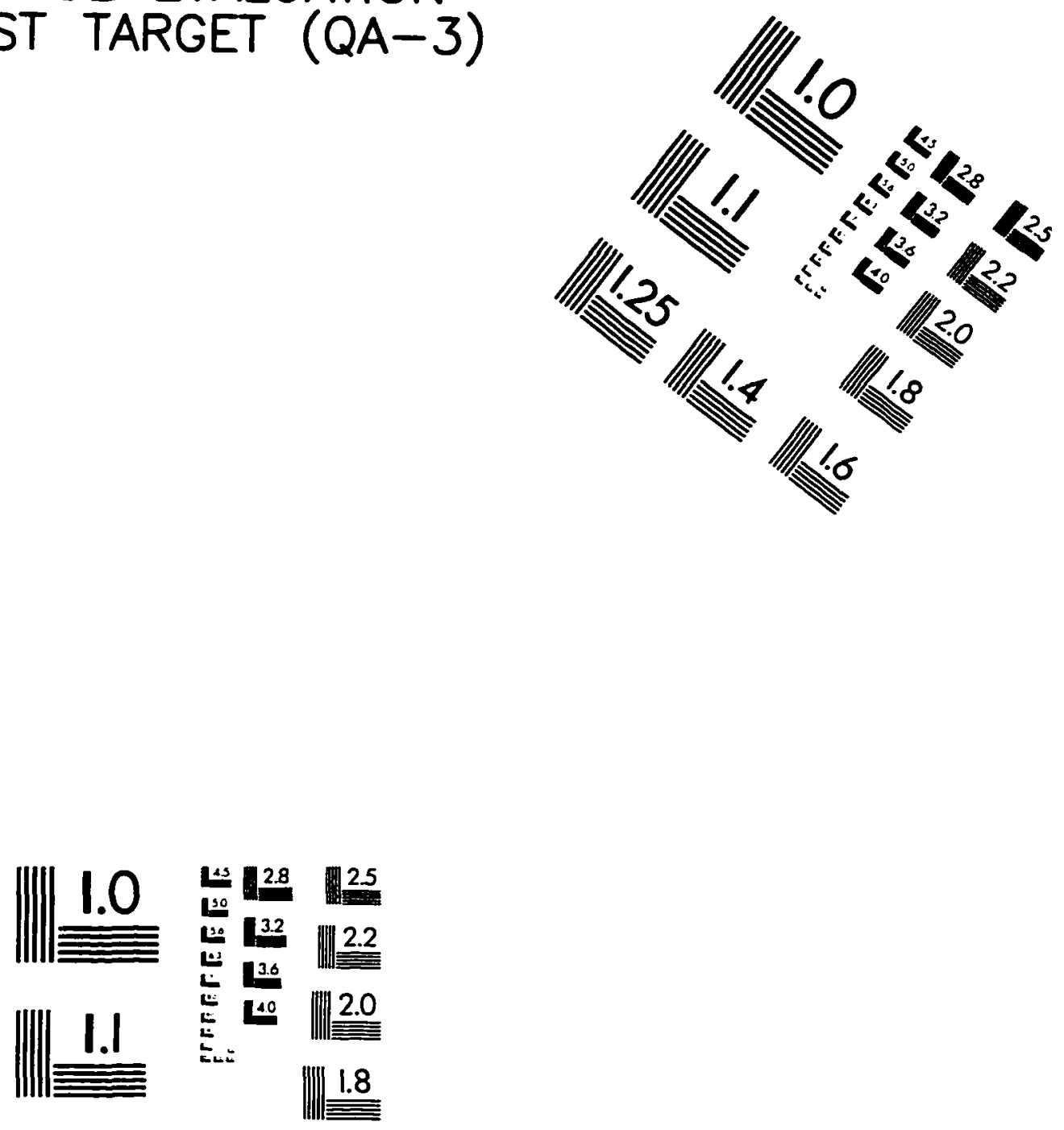

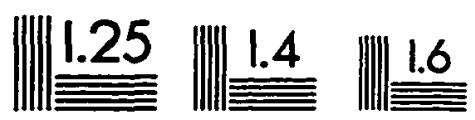
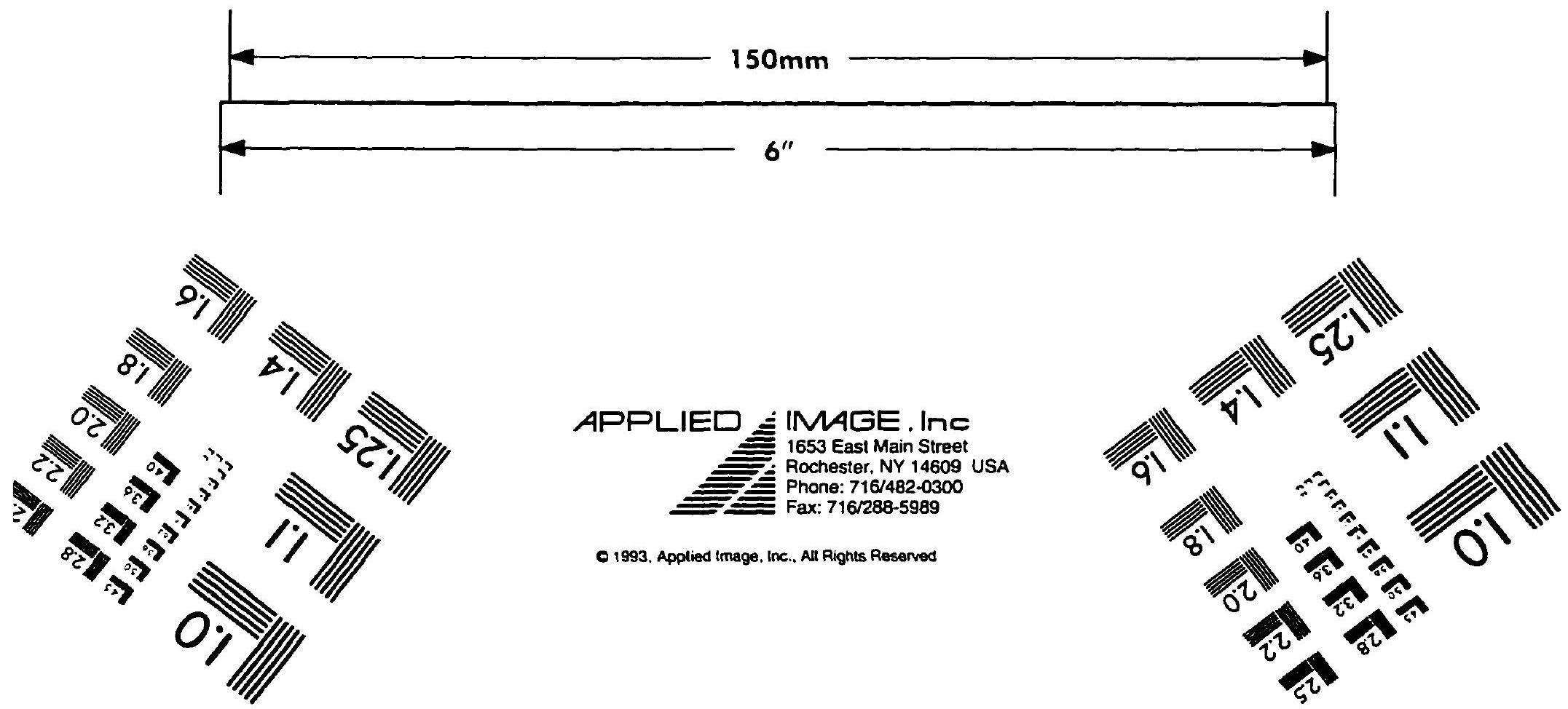

Reproduced with permission of the copyright owner. Further reproduction prohibited without permission. 